\title{
Human myelin protein P2: from crystallography to time-lapse membrane imaging and neuropathy-associated variants
}

\author{
Maiju Uusitalo ${ }^{1}$, Martin Berg Klenow ${ }^{2}$, Saara Laulumaa ${ }^{1,3}$, Matthew P. Blakeley ${ }^{4}$, \\ Adam Cohen Simonsen ${ }^{2}$, Salla Ruskamo ${ }^{1}$ (iD and Petri Kursula ${ }^{1,5}$ (D) \\ 1 Faculty of Biochemistry and Molecular Medicine \& Biocenter Oulu, University of Oulu, Finland \\ 2 Department of Physics, Chemistry and Pharmacy, University of Southern Denmark, Odense, Denmark \\ 3 European Spallation Source, Lund, Sweden \\ 4 Large-Scale Structures Group, Institut Laue-Langevin, Grenoble, France \\ 5 Department of Biomedicine, University of Bergen, Norway
}

\author{
Keywords \\ Charcot-Marie-Tooth disease; fatty acid- \\ binding protein; lipid binding; mutation; \\ myelin protein $\mathrm{P} 2$; protein structure

\section{Correspondence Molecular Medicine \& Biocenter Oulu, \\ University of Oulu, Oulu, Finland \\ Tel: +358294481187 \\ E-mail: salla.ruskamo@oulu.fi (S.R.) \\ and \\ P. Kursula, Department of Biomedicine, University of Bergen, Bergen, Norway Tel: +47-55586438 \\ E-mail: petri.kursula@uib.no (P.K.)} \\ S. Ruskamo, Faculty of Biochemistry and
}

(Received 20 April 2021, revised 10 June 2021, accepted 16 June 2021)

doi:10.1111/febs.16079
Peripheral myelin protein $2(\mathrm{P} 2)$ is a fatty acid-binding protein expressed in vertebrate peripheral nervous system myelin, as well as in human astrocytes. Suggested functions of P2 include membrane stacking and lipid transport. Mutations in the $P M P 2$ gene, encoding $\mathrm{P} 2$, are associated with Charcot-Marie-Tooth disease (CMT). Recent studies have revealed three novel PMP2 mutations in CMT patients. To shed light on the structure and function of these $\mathrm{P} 2$ variants, we used X-ray and neutron crystallography, small-angle X-ray scattering, circular dichroism spectroscopy, computer simulations and lipid binding assays. The crystal and solution structures of the I50del, M114T and V115A variants of P2 showed minor differences to the wild-type protein, whereas their thermal stability was reduced. Vesicle aggregation assays revealed no change in membrane stacking characteristics, while the variants showed altered fatty acid binding. Time-lapse imaging of lipid bilayers indicated formation of doublemembrane structures induced by $\mathrm{P} 2$, which could be related to its function in stacking of two myelin membrane surfaces in vivo. In order to better understand the links between structure, dynamics and function, the crystal structure of perdeuterated P2 was refined from room temperature data using neutrons and X-rays, and the results were compared to simulations and cryocooled crystal structures. Our data indicate similar properties for all known human P2 CMT variants; while crystal structures are nearly identical, thermal stability and function of CMT variants are impaired. Our data provide new insights into the structure-function relationships and dynamics of $\mathrm{P} 2$ in health and disease.

\footnotetext{
Abbreviations

CMT, Charcot-Marie-Tooth disease; CNS, central nervous system; DAUDA, 11-dansylaminoundecanoid acid; DiD-C18, 1,1'-dioctadecyl3,3,3', 3'-tetramethylindodicarbocyanine; DMPC, 1,2-dimyristoyl-sn-glycero-3-phosphocholine; DMPG, 1,2-dimyristoyl-sn-glycero-3phosphorylglycerol; DOPC, 1,2-dioleoyl-sn-glycero-3-phosphocholine; DOPS, 1,2-dioleoyl-sn-glycero-3-phospho-L-serine; DTT, 1,4dithiothreitol; FABP, fatty acid-binding protein; MD, molecular dynamics; NCV, nerve conduction velocity; P2, peripheral myelin protein 2; $P M P 2$, peripheral myelin protein 2 gene; PNS, peripheral nervous system; RT, room temperature; SAXS, small-angle X-ray scattering; SECSAXS, small-angle $X$-ray scattering combined with size-exclusion chromatography; TEV, tobacco etch virus; $T_{m}$, melting temperature.
} 


\section{Introduction}

The neuronal axons of the peripheral nervous system (PNS) are surrounded by multilamellar Schwann cell membrane protrusions, called myelin. Myelin sheaths comprise over 40 membrane lamellae providing a high-resistance and low-capacitance sheath for saltatory impulse conduction. The myelin membrane has uniquely high lipid content $(\sim 70 \%)$, and very few proteins are enriched in compact myelin, maintaining the proper insulating structure of the myelin sheath.

Human peripheral myelin protein $2(\mathrm{P} 2)$, encoded by the $P M P 2$ gene, is a $14-\mathrm{kDa}$ fatty acid-binding protein (FABP), expressed by Schwann cells in the vertebrate PNS [1] and astrocytes in human central nervous system (CNS) [2]. P2 first appeared in tetrapods, but the origins of $\mathrm{P} 2$ can be traced to invertebrate paralogs. P2 orthologs are limited to tetrapods, although paralogs, that is other FABPs, are present in fishes and invertebrates. P2 is less conserved among mammals than other compact myelin proteins [3], which may hint at diverging importance and function for P2 between species.

According to current knowledge, the main functions of $\mathrm{P} 2$ are associated with lipids. P2 stacks lipid bilayers and may transport lipids, such as fatty acids or cholesterol, within myelin membranes [4-8]. P2 binds to lipid bilayers via two opposing faces, sticking membranes together with a constant spacing $[7,8]$. P2 plays a role in maintaining the glial cell lipid homeostasis [6] and remyelination of peripheral nerves after a nerve injury [9]. A number of recent studies have highlighted a novel intriguing function of $\mathrm{P} 2$ in human astrocytes $[2,10]$, while it is absent from mouse astrocytes. Altered PMP2 expression patterns have been observed in various cancers [10-12], as well as in pathological conditions of the inner ear [13].

Point mutations in the $P M P 2$ gene have been linked to Charcot-Marie-Tooth disease (CMT) [14-17], a genetically heterogeneous group of motor and sensory neuropathies caused by mutations in $>100$ target genes. Globally, CMT is the most common inherited neuropathy with a prevalence of $1: 2500$ [18]. CMT can be classified into three main types: demyelinating (CMT1), axonal (CMT2) and intermediate (I-CMT) [19]. $40-50 \%$ of all CMT patients have CMT1 [20], which is characterized by the loss of myelin and reduction of the nerve conduction velocities $(\mathrm{NCVs})$ to $<35 \mathrm{~m} \cdot \mathrm{s}^{-1}$. Generally, individuals with myelindamaging mutations develop symptoms at the age of $5-25$. Symptoms include slowly progressive distal muscle weakness and atrophy, as well as sensory loss, often associated with the pes cavus foot deformity and bilateral foot drop [21].

Crystal structures of bovine [22], equine [23] and human P2 have been determined $[4,7,24]$. P2 is a small $\beta$-barrel protein folded like other FABPs, with a cap formed by two $\alpha$-helices. P2 has two membranebinding sites on opposite sides of the protein; the ends of the $\beta$-barrel are positively charged while the top of the $\alpha$-helical cap is hydrophobic. Inside the $\beta$-barrel, a fatty acid is bound in the crystal structures. Subatomic resolution crystal structures have revealed an unexpected protonation state for one of the Arg residues coordinating the bound fatty acid [7,24]. It is likely that the fatty acid ligand mimics lipids transported by $\mathrm{P} 2$, although a structural role for the ligand cannot be excluded.

Crystal structures of $\mathrm{P} 2$ variants have shed light on the details of $\mathrm{P} 2$ dynamics, membrane interactions and portal region control $[8,24,25]$. Three CMT1-linked P2 mutations have been previously studied at the molecular level [26]. These autosomal dominant mutations include I43N [14,15], T51P and I52T [16,17]. These three P2 disease variants have crystal structures similar to the wild-type protein, but their thermal stability and biochemical binding properties are affected. T51P is the most differing variant, with more open solution structure conformations, altered membrane interactions and reduced solubility [26].

Recently, two novel CMT1-associated P2 point mutations; p.M114T (c.341T $>$ C) and p.V115A (c.344T $>C$ ) were found in Bulgarian and German families, respectively [27]. The Bulgarian family with M114T suffered low NCVs, $<15 \mathrm{~m} \cdot \mathrm{s}^{-1}$, of the motor fibres of median and ulnar nerves. In contrast, the German patients with the V115A mutation showed only mild changes in NCVs [27]. A third recently discovered P2 patient mutation, an in-frame deletion of Ile50 (I50del, c. 147-149delTAT), results in CMT1 with an early-onset demyelinating neuropathy with foot deformity and gait impairment. The reduced motor $\mathrm{NCV}$ s in patients with the I50del mutation indicate neuropathy in lower and upper limbs, but no defects in sensory nerves were observed [28].

In the present study, we describe the high-resolution crystal structures of the three recently discovered CMT-associated P2 variants: I50del, M114T and V115A. The thermal stability and lipid binding of these variants were investigated using circular dichroism (CD) spectroscopy, lipid vesicle aggregation assays, time-lapse imaging of supported lipid bilayers and fatty acid-binding assays. In addition, a room temperature (RT) crystal structure of human P2 is reported through a joint neutron/X-ray refinement and 
used together with molecular dynamics (MD) simulations to get further information on P2 flexibility.

\section{Results}

$\mathrm{P} 2$ is a small $\beta$-barrel protein of the FABP family (Fig. 1). Previously, we studied the structure-function relationships in three CMT-linked variants: I43N, T51P and I52T [26]. Now, three more disease variants have been reported: I50del, M114T and V115A [27,28]. On the wild-type P2 (P2-wt) 3D structure [4], all six CMT-linked mutations are clustered close to one another (Fig. 1).

To elucidate the structure and function of the three recently discovered $\mathrm{P} 2$ variants, we expressed and purified V115A, M114T and I50del. All the variants behaved well, and none of them showed signs of aggregation during purification or further analysis. We used both experimental and in silico techniques to study the effects of the P2 patient mutations on structure and function at the molecular level.

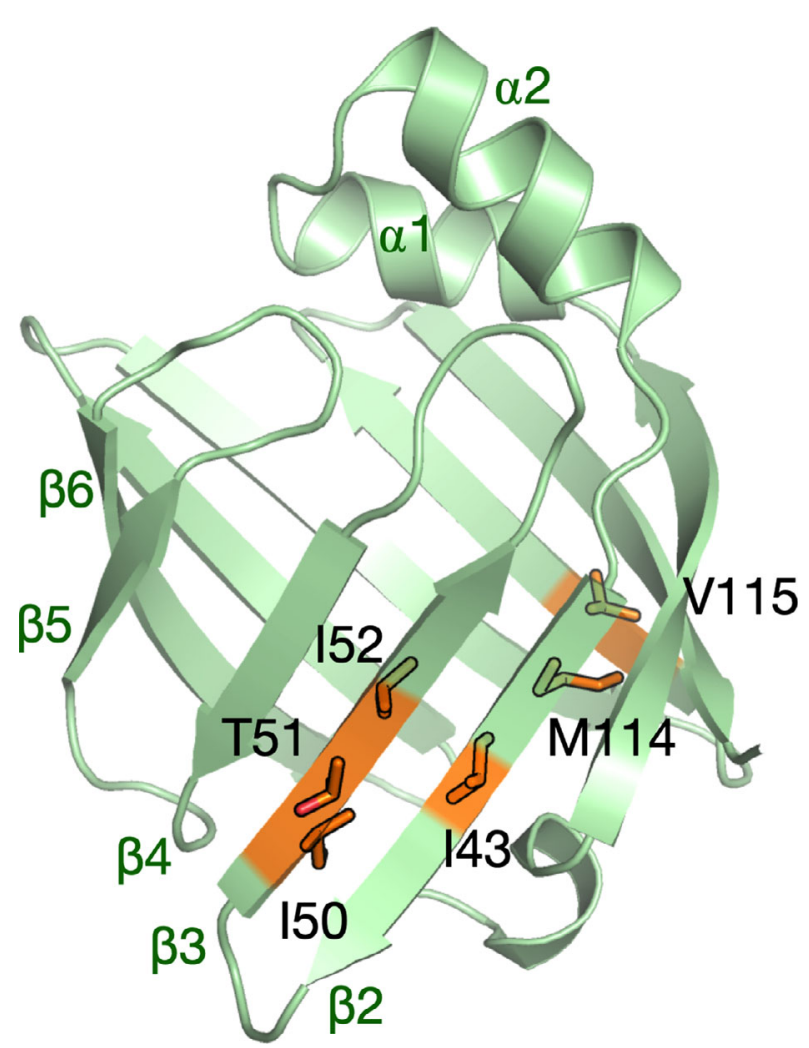

Fig. 1. Overall structure of human P2. The locations of all known CMT-linked mutations on the protein structure have been indicated (orange) and labelled. Key secondary structure elements are indicated in green. Structure rendered using PyMOL.

\section{The crystal structures of $\mathrm{CMT}$-linked $\mathrm{P} 2$ variants}

P2-I50del, M114T and V115A were crystallized, and structures of all variants were refined at high resolution (Table 1). The asymmetric unit of I50del and M114T contained a single protein molecule, whereas that of V115A had two P2 molecules. The overall fold of all variants, with a $\beta$-barrel covered by an $\alpha$-helical lid, remained unchanged in comparison with P2-wt. In the V115A crystal structure, the $\alpha$-helical lid and hinge regions of two molecules face each other. All structures contained a palmitate molecule bound inside the $\beta$ barrel. The CMT mutation sites are situated at the bottom of the $\beta$ barrel (Fig. 1). Ile50 is located on strand $\beta 3$, whereas M114T and V115A are located on strand $\beta 9$ on the opposite side of the $\beta$ barrel (Fig. 2A).

The I50del mutation is located at the beginning of the $\beta 3$ strand in the close proximity of the $\beta 2-\beta 3$ loop. The deletion shortens the loop and locally changes the sequence register, but it has no effect on the hydrogen bonding of the $\beta$ sheet (Fig. 2B). In both P2-wt and the mutant, the side chain of Asp48 interacts with the Lys66 side chain, located in the loop $\beta 4-\beta 5$. In P2-wt, Asp48 is situated near the tip of the $\beta 2-\beta 3$ loop, while in $150 \mathrm{del}$, this residue lies closer to the central region of the $\beta$ barrel, at the beginning of strand $\beta 3$. In P2wt, Ile49 occupies this position.

In our crystal structures, both M114T and V115A have minor effects on the conformation or the hydrogen bonding of the amino acids surrounding the mutation sites (Fig. 2C,D). Met114 points towards the fatty acid inside the $\beta$ barrel, but does not directly interact with the bound ligand (Fig. 2C). Arg107, located close to Met114 on the adjacent $\beta$ strand ( $\beta 8$ ), interacts directly with the bound palmitic acid. This residue adopts two side-chain conformations in the M114T structure, indicating additional space and flexibility in the mutant protein. In one of these conformations, the Arg107 guanidino group distance to the carboxyl group of palmitic acid is longer, possibly altering the fatty acid-binding affinity of the M114T variant. Additionally, two extra water molecules are present in a cavity caused by the M114T mutation (Fig. 2C). These water molecules form hydrogen bonds to Arg107 and Thr114 side chains, respectively.

Val115, on the other hand, is exposed and points outwards from the $\beta$ barrel (Fig. 2D); its side chain forms van der Waals interactions with neighbouring residues. On the protein surface, Val115 is situated in the middle of a small strip of hydrophobic and charged residues. The V115A mutation slightly changes the conformation of these residues and 
Table 1. Data processing and structure refinement statistics. The processing statistics of the neutron dataset have been reported before [55].

\begin{tabular}{|c|c|c|c|c|c|}
\hline Variant & |50del & M114T & V115A & P2-wt X-ray & P2-wt neutron \\
\hline PDB ID & 7NSR & 7NRW & 7NTP & 7060 & \\
\hline \multicolumn{6}{|l|}{ Data collection } \\
\hline Beamline & P11/PETRA III & P13/PETRA III & P11/PETRA III & rotating anode & LADI-III/ILL \\
\hline X-ray wavelength $(\AA)$ & 1.033 & 0.976 & 1.033 & 1.54 & $3.0-3.9$ \\
\hline Space group & P 41212 & P 41212 & 1222 & P 41212 & P 41212 \\
\hline Unit cell dimensions $a, b, c(\AA)$ & $\begin{array}{l}66.14,66.14 \\
101.19\end{array}$ & $\begin{array}{l}64.7964 .79 \\
100.93\end{array}$ & $\begin{array}{l}85.4791 .22 \\
107.05\end{array}$ & $\begin{array}{l}58.7258 .72 \\
101.89\end{array}$ & $\begin{array}{l}57.9557 .95 \\
100.79\end{array}$ \\
\hline$\alpha, \beta, \gamma\left({ }^{\circ}\right)$ & $90,90,90$ & $90,90,90$ & $90,90,90$ & $90,90,90$ & $90,90,90$ \\
\hline Resolution range $(\AA)$ & $\begin{array}{l}50-1.50(1.54- \\
1.50)\end{array}$ & $\begin{array}{l}50-2.00(2.05- \\
2.00)\end{array}$ & $\begin{array}{l}50-2.10(2.15- \\
2.10)\end{array}$ & $\begin{array}{l}15-2.00(2.06- \\
2.00)\end{array}$ & $\begin{array}{l}40-2.40(2.53- \\
2.40)\end{array}$ \\
\hline No. unique reflections & 36645 (2657) & 15135 (1092) & 24729 (1814) & 12464 (891) & 4232 (363) \\
\hline Completeness (\%) & 99.9 (99.3) & 99.9 (99.7) & 99.7 (99.9) & $98.9(96.1)$ & $60.1(36.9)$ \\
\hline Redundancy & $13.9(13.7)$ & $13.8(13.5)$ & $4.9(5.0)$ & $9.7(3.2)$ & $4.2(2.2)$ \\
\hline $\mathrm{R}_{\mathrm{sym}}(\%)$ & $6.6(573.4)$ & $24.5(326.7)$ & $7.0(254.6)$ & $6.0(43.1)$ & $18.9(30.4)$ \\
\hline$R_{\text {meas }}(\%)$ & $6.9(595.8)$ & $25.5(339.6)$ & $7.8(285.0)$ & $6.3(51.3)$ & - \\
\hline$<|/ \sigma|>$ & $17.6(1.1)$ & $11.6(1.2)$ & $11.2(0.9)$ & $25.2(3.0)$ & $6.1(2.8)$ \\
\hline $\mathrm{CC}_{1 / 2}(\%)$ & $99.9(74.3)$ & $99.4(70.3)$ & $99.8(26.1)$ & $99.9(84.9)$ & - \\
\hline Wilson $B\left(\AA^{2}\right)$ & 25.9 & 44.6 & 58.98 & 34.3 & - \\
\hline \multicolumn{6}{|l|}{ Structure refinement } \\
\hline $\mathrm{R}_{\text {cryst }} / \mathrm{R}_{\text {free }}(\%)$ & 18.2/19.9 & $20.7 / 25.0$ & $23.7 / 28.9$ & $15.5 / 20.3$ & $29.5 / 34.1$ \\
\hline RMSD bond lengths $(\AA)$ & 0.022 & 0.012 & 0.0059 & 0.029 & \\
\hline RMSD bond angles $\left({ }^{\circ}\right)$ & 1.880 & 1.1 & 0.808 & 2.1 & \\
\hline MolProbity score (percentile) & 1.72 (67th) & 0.66 (100th) & 1.49 (98th) & 2.03 (71st) & \\
\hline Ramachandran favoured/outliers (\%) & $97.7 / 0$ & $100 / 0$ & $96.2 / 0$ & $97.7 / 0.8$ & \\
\hline
\end{tabular}

thereby may somewhat affect the surface electrostatics of P2. Another unique feature in the V115A structure is observed in loop $\beta 3-\beta 4$ of chain $A$; the side chain of Phe58 has flipped outwards and the palmitic acid is shifted closer to the loop.

\section{Solution structures of $\mathbf{P} 2$ variants}

As seen above, the crystal structures of all CMTassociated P2 mutants closely resemble P2-wt. However, in a study on previously discovered P2 mutations, we observed changes in the solution behaviour in two CMT variants, whereby they opened up in solution [26]. This opening may be a functional property of $\mathrm{P} 2$ during lipid ligand entry and egress, as well as lipid bilayer binding $[8,24]$. Hence, we used synchrotron small-angle X-ray scattering (SAXS) to study, if the P2 variant solution structures differ from P2-wt.

All variants behaved well in the SAXS measurements, and the Guinier regions were linear, in line with a monodisperse monomeric sample. The SAXS scattering curves and distance distributions of $\mathrm{P} 2$-wt and the disease variants were similar (Fig. 3A,B); the radius of gyration $\left(\mathrm{R}_{\mathrm{g}}\right)$ and maximum distance $\left(\mathrm{D}_{\max }\right)$ remained unchanged (Table 2). For P2-wt, the crystal and solution structures were nearly identical (Fig. 3C,D). The results confirm that, in line with the crystal structures, the solution structures of the CMT-linked variants are similar to that of $\mathrm{P} 2$-wt.

\section{Thermal stability and folding}

CD spectroscopy was used to compare the secondary structure content and thermal stability of the P2 variants (Fig. 4). The shape of the CD spectra of the variants and P2-wt was similar (Fig. 4A), but the intensity of the positive and negative peak maxima varied slightly; this may indicate slightly different average degrees of folding in solution or-more likely - minor errors in concentration.

We studied thermal stability and measured the melting temperatures $\left(T_{m}\right)$ using $C D$. The $T_{m}$ for $P 2-w t$ was $+61.6{ }^{\circ} \mathrm{C}$, whereas I50del showed much lower $\mathrm{T}_{\mathrm{m}}$ $\left(+46.3{ }^{\circ} \mathrm{C}\right.$; Fig. $4 \mathrm{~B}$, Table 3 ). The $\mathrm{T}_{\mathrm{m}}$ of the missense variants $\mathrm{M} 114 \mathrm{~T}$ and $\mathrm{V} 115 \mathrm{~A}$ were $+49.2{ }^{\circ} \mathrm{C}$ and $+56.3{ }^{\circ} \mathrm{C}$, respectively, also showing a decrease in thermal stability (Fig. 4B, Table 3). Thus, although the crystal and solution structures of the P2 disease variants were nearly unchanged compared to P2-wt, the thermal stability of the CMT-associated variants is remarkably reduced and may affect the function of these variants in vivo. 

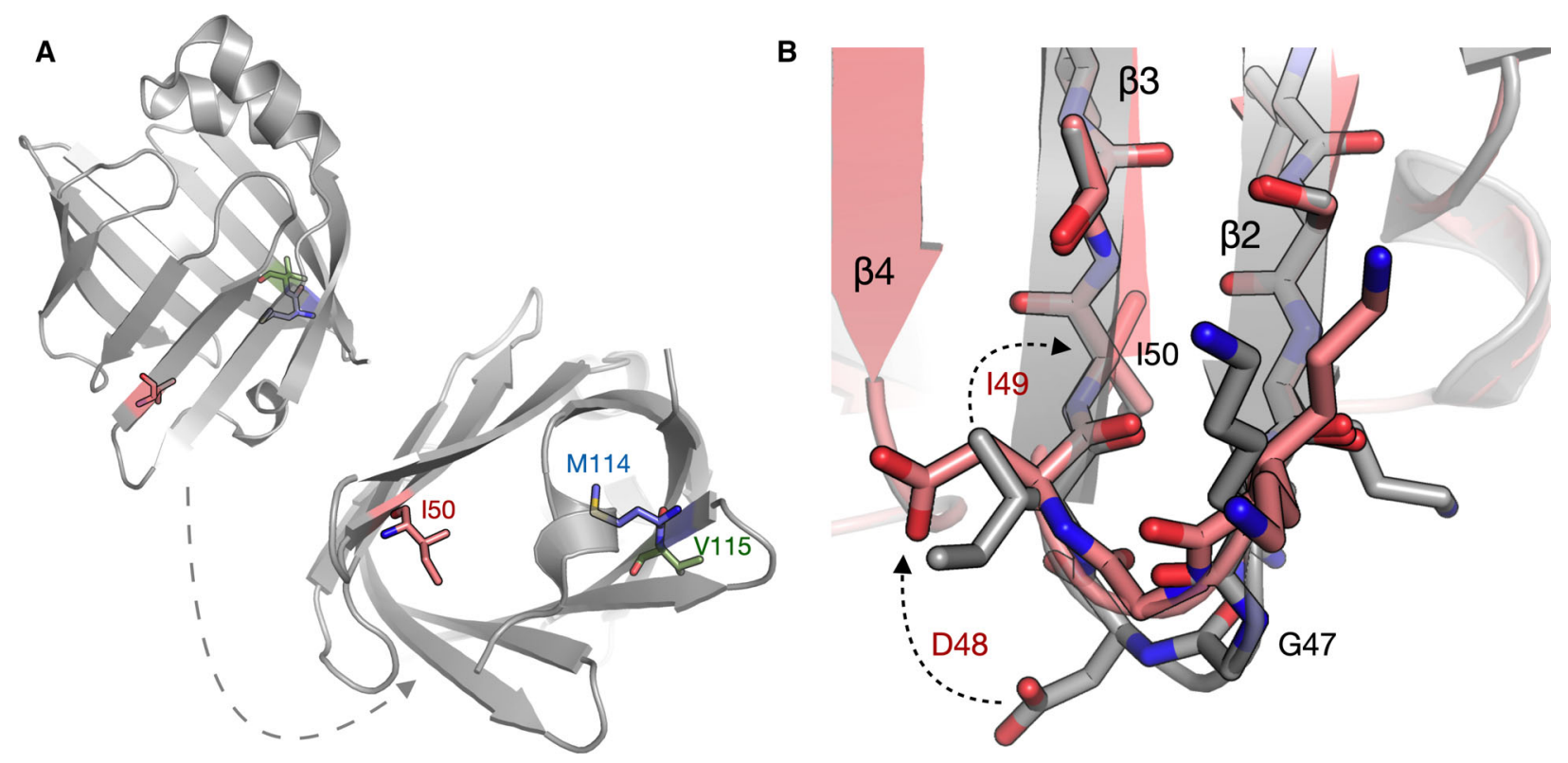

C
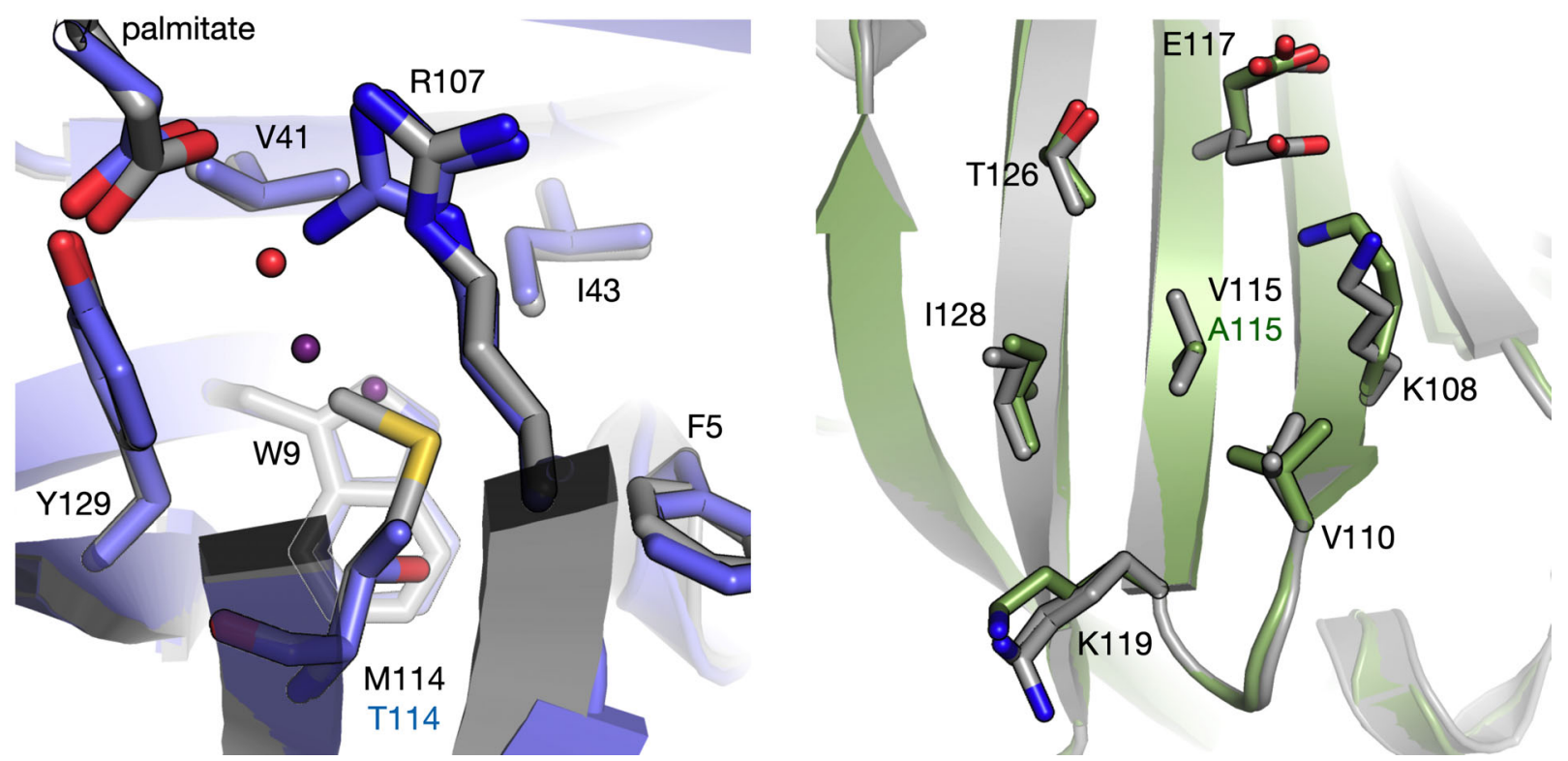

Fig. 2. Crystal structures of new $C M T$ variants of human $P 2$. (A) Overall view from the side and bottom of $P 2$, highlighting the locations of Ile50 (pink), Met114 (blue) and Val115 (green). (B) Comparison of P2-wt (grey) and I50del (pink). The deletion of Ile50 leads to Ile49 taking its buried position and a change of register in the $\beta 2-\beta 3$ loop. (C) Comparison of P2-wt (grey) and M114T (blue). Arg107 is in a double conformation in $\mathrm{M} 114 \mathrm{~T}$, and the cavity resulting from the mutation has two new water molecules (blue spheres). P2-wt has one structural water molecule nearby (red sphere). (D) Comparison of P2-wt (grey) and V115A (green). Val115 is in a central position on the $\beta$ sheet surface, and the mutation causes some rearrangements of nearby residues through altered van der Waals interactions. Structures rendered using PyMOL.

\section{MD simulations}

The dynamics of wild-type and mutant P2 were studied with $>1-\mu$ S MD simulations in water. The starting points for the simulations were the individual crystal structures. The RMSF and RMSD plots (Fig. 5A,B) were analysed to detect local and global differences in dynamics coupled to the mutations. Furthermore, plots of $\mathrm{R}_{\mathrm{g}}$ and the opening of the $\mathrm{P} 2$ barrel were followed through the simulation (Fig. 5C,D). 

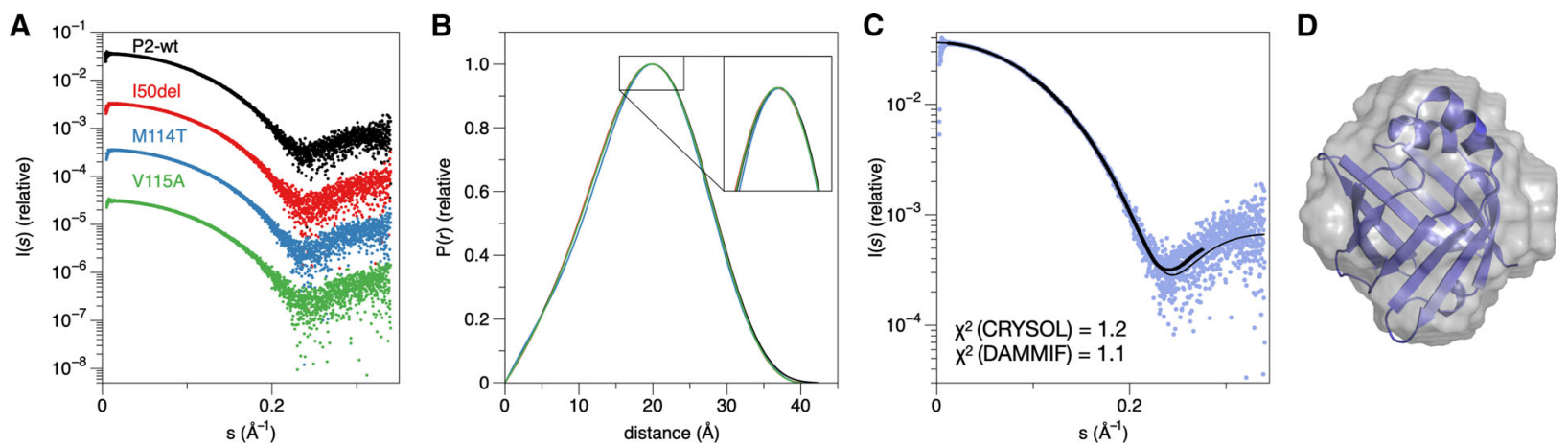

Fig. 3. Solution studies on P2 mutants using SAXS. (A) Scattering curves from a SEC-SAXS experiment. (B) The distance distribution function indicates essentially identical structures in solution for all 4 samples. (C) Fits of the crystal structure (thin line) and a dummy atom model (thick line) to the raw data. (D) P2-wt crystal structure (blue cartoon) superimposed on the ab initio dummy atom model based on SAXS. The model reflects a closed conformation. Structure rendered using PyMOL.

Table 2. SAXS parameters.

\begin{tabular}{llll}
\hline sample & $\mathrm{R}_{\mathrm{g}}(\AA)$ & $\mathrm{D}_{\max }(\AA)$ & $\mathrm{V}_{\text {porod }}\left(\AA^{3}\right)$ \\
\hline P2-wt & $14.72 \pm 0.34$ & 42.3 & 17400.90 \\
I50del & $14.65 \pm 0.28$ & 40.3 & 17080.10 \\
M114T & $14.65 \pm 0.05$ & 40.4 & 16829.60 \\
V115A & $14.63 \pm 0.06$ & 40.2 & 15843.20 \\
\hline
\end{tabular}

The results indicate, as expected, highest mobility for the loop regions of the $\beta$ barrel, especially in the $\beta 5-\beta 6$ region around residues $75-80$ (Fig. 5E). The M114T mutant had higher RMSF values, indicating an overall effect on protein dynamics by this nonconservative mutation of a buried residue side chain. I50del, on the other hand, was less dynamic than the other variants, which correlates with its short $\beta 2-\beta 3$ loop.

\section{Crystal structure of perdeuterated human P2 at RT}

All published human P2 crystal structures thus far have been determined from cryocooled crystals at $100 \mathrm{~K}$. In order to gain additional insights into P2 structure and dynamics, the P2 crystal structure was here determined at RT. To this end, crystals of perdeuterated human P2 [7,29] were subjected to both neutron and X-ray diffraction data collection at RT. A joint refinement using both datasets was then carried out, and the RT crystal structure was compared to the structure at $100 \mathrm{~K}$ as well as to the MD data.

$\mathrm{B}$ factor analysis reveals that while the overall shape of the $\mathrm{B}$ factor plot is similar, the $\beta 5-\beta 6$ hairpin loop is more dynamic at RT (Fig. 6A,B). This segment corresponds to the strands in the $\beta$ barrel, which present a large conformational change upon $\beta$ barrel opening $[8,24,26]$. When $\mathrm{P} 2$ binds to a lipid bilayer, the $\beta 5-\beta 6$ unit flaps open and interacts directly with the membrane surface lipid headgroups [8]. The RT crystal structure is in line with high flexibility of the portal region and especially strands $\beta 5-\beta 6$. Examples of electron and nuclear density maps of the RT structure of $\mathrm{P} 2$ are shown in Fig. 6C-E.

Comparing to the MD simulation data, the RT structure complements the story. In MD simulations, especially for M114T (Fig. 5D,E), the $\beta 5-\beta 6$ flap is the most mobile segment, while its $\mathrm{B}$ factors are low in cryocooled crystals. A clear increase in the mobility of the $\beta 5-\beta 6$ segment is seen in the RT crystal structure, pointing towards a functionally relevant difference between RT and cryocooled crystal structures.

\section{Bioinformatics analyses for the mutations}

The sequence conservation of P2 among selected vertebrates was studied with multiple sequence alignments (Fig. 7A), and the conserved residues were mapped onto the P2 crystal structure (Fig. 7B,C). The conservation has interesting patterns; essentially every second residue on the $\beta$ strands is conserved, corresponding to inward-pointing side chains. In addition, the inside of helix $\alpha 1$ and the outside of helix $\alpha 2$ are conserved. The latter is hydrophobic and expected to be embedded in the bilayer core upon membrane binding [7,8], while helix $\alpha 1$ interacts with the bound fatty acid. Furthermore, the loop $\beta 2-\beta 3$ and strands $\beta 4-\beta 5$ are conserved, as is Pro39, which is important for P2 dynamics and membrane interactions [7,30].

A sequence-based prediction of rigidity was carried out using DynaMine. All three mutations were predicted to cause an increase in local flexibility of the P2 


\section{A}

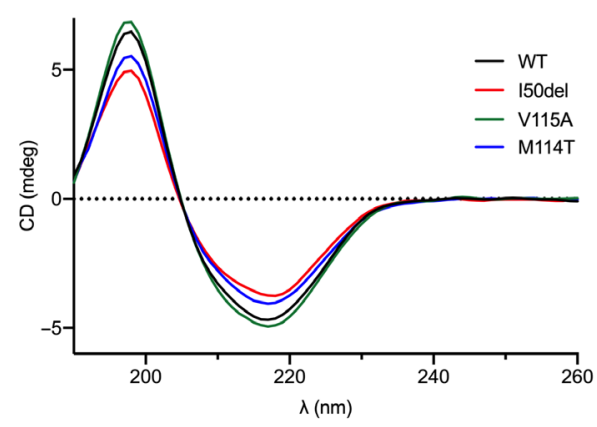

B
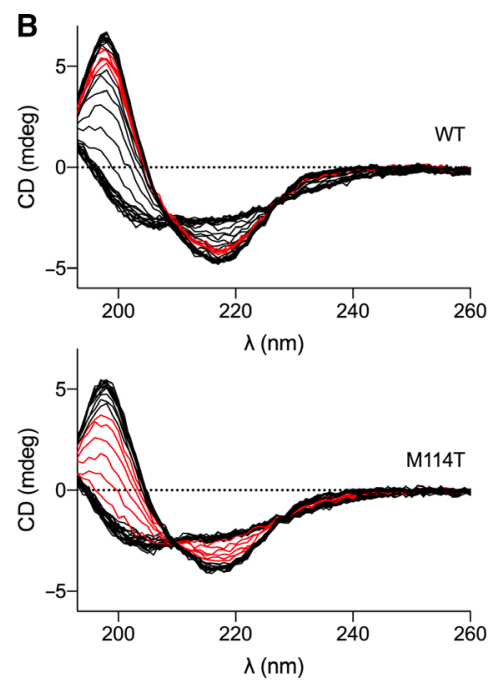
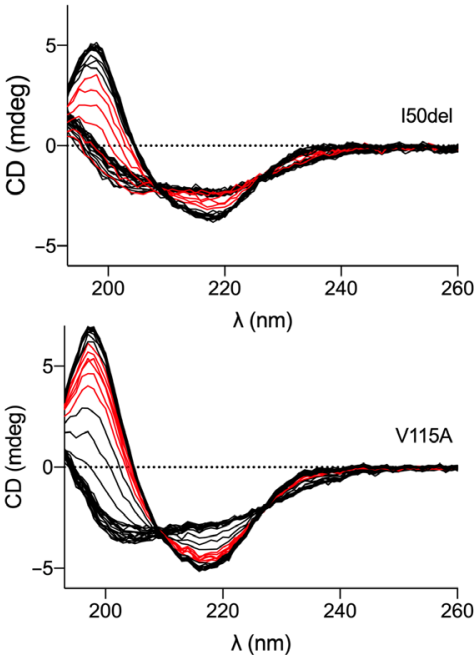

Fig. 4. Folding and thermal stability. (A) $C D$ spectra of $P 2-w t$ and the 3 variants. (B) Assay of thermal stability. The measured CD curve is shown every 2 degrees upon heating, with the temperature range from +46 to $+56{ }^{\circ} \mathrm{C}$ shown in red for each variant.

Table 3. Summary of structure and function of currently known human $P 2$ disease variants. $\Delta T_{m}$ is given relative to $P 2-w t$ in each individual study.

\begin{tabular}{|c|c|c|c|c|c|c|c|}
\hline Mutation & $\begin{array}{l}\text { Structural } \\
\text { features }\end{array}$ & Location & $\begin{array}{l}\Delta \mathrm{T}_{\mathrm{m}} \\
\left({ }^{\circ} \mathrm{C}\right)\end{array}$ & $\begin{array}{l}\text { Fatty acid } \\
\text { binding }\end{array}$ & $\begin{array}{l}\text { Membrane } \\
\text { stacking }\end{array}$ & Phenotype & References \\
\hline I43N & $\begin{array}{l}\text { Open in } \\
\text { solution }\end{array}$ & $\begin{array}{l}\beta 2, \\
\text { inwards }\end{array}$ & -17 & Increased & Unstable & $\begin{array}{l}\text { Reduced NCVs }\left(11-21 \mathrm{~m} \cdot \mathrm{s}^{-1}\right) \text {, mild or moderate } \\
\text { muscle weakness and atrophy, foot } \\
\text { malformation, abnormal myelin, onion bulbs, } \\
\text { neuronal abnormalities in zebrafish, reduced } \\
\text { performance in rotador test and reduced } \\
\text { amount of large myelinated axons in transgenic } \\
\text { mice }\end{array}$ & {$[14,15,26]$} \\
\hline |50del & $\begin{array}{l}\beta 2-\beta 3 \text { loop } \\
\text { shorter }\end{array}$ & $\begin{array}{l}\text { Start of } \\
\beta 3, \\
\text { inwards }\end{array}$ & -16 & Normal & Normal & $\begin{array}{l}\text { Reduced NCVs }\left(\sim 20-30 \mathrm{~m} \cdot \mathrm{s}^{-1}\right) \text {, equinus foot } \\
\text { deformity and gait impairment }\end{array}$ & $\begin{array}{l}\text { [28], this } \\
\text { study }\end{array}$ \\
\hline T51P & $\begin{array}{l}\text { Open in } \\
\text { solution; } \\
\text { tends to } \\
\text { aggregate }\end{array}$ & $\begin{array}{l}\beta 3, \\
\text { outwards }\end{array}$ & -24 & Increased+ & Decreased & $\begin{array}{l}\text { Reduced NCVs }\left(\sim 11 \mathrm{~m} \cdot \mathrm{s}^{-1}\right) \text {, severe muscle } \\
\text { weakness and atrophy, foot malformation }\end{array}$ & {$[16,26]$} \\
\hline $152 \mathrm{~T}$ & $\begin{array}{l}\text { Loss of } \mathrm{H} \\
\text { bonds }\end{array}$ & $\begin{array}{l}\beta 3, \\
\text { inwards }\end{array}$ & -13 & Increased & Unstable & $\begin{array}{l}\left.\text { Reduced NCVs (14-21 } \mathrm{m} \cdot \mathrm{s}^{-1}\right) \text {, muscle weakness } \\
\text { and atrophy in lower and upper limbs, reduced } \\
\text { density of myelinated axons and thickness of } \\
\text { myelin, onion bulbs }\end{array}$ & {$[16,26]$} \\
\hline M114T & $\begin{array}{l}\text { Extra water } \\
\text { molecules, } \\
\text { increased } \\
\text { dynamics }\end{array}$ & $\begin{array}{l}\text { Start of } \\
\beta 9, \\
\text { inwards }\end{array}$ & -13 & Increased & Normal & $\begin{array}{l}\text { Reduced NCVs }\left(<20 \mathrm{~m} \cdot \mathrm{s}^{-1}\right) \text {, frequent falls, } \\
\text { muscle weakness, severe demyelination and } \\
\text { secondary axonal degeneration }\end{array}$ & $\begin{array}{l}\text { [27], this } \\
\text { study }\end{array}$ \\
\hline V115A & $\begin{array}{l}\text { Altered surface } \\
\text { properties }\end{array}$ & $\begin{array}{l}\beta 9, \\
\text { outwards }\end{array}$ & -6 & Increased & Normal & $\begin{array}{l}\text { Mostly normal NCVs, clumsiness, foot deformity, } \\
\text { variable and very mild demyelination and focal } \\
\text { pattern of distribution along peripheral nerves }\end{array}$ & $\begin{array}{l}\text { [27], this } \\
\text { study }\end{array}$ \\
\hline
\end{tabular}


Fig. 5. MD simulation of $P 2-w t$ and $C M T$ variants. (A) RMSF plots during the simulation. (B) $\mathrm{C} \alpha \mathrm{RMSD}$ compared to the starting structure. (C) $R_{g}$ during the simulation. (D) Opening of the $\beta$ barrel between strands $\beta 4$ and $\beta 5$, indicated by the distance between the $\mathrm{C} \alpha$ atoms of residues 61 and 74 and linked to the movement of the $\beta 5-\beta 6$ unit away from the helical lid. (E) Snapshot of the opened M114T structure at a time point of $920 \mathrm{~ns}$ (blue), overlaid with the crystal structure (grey). The anion-binding site is indicated with a magenta sphere, and the bound palmitate molecules are shown as sticks. Opening of the $\beta 5-\beta 6$ unit is indicated by the arrow. Structure rendered using PYMOL.
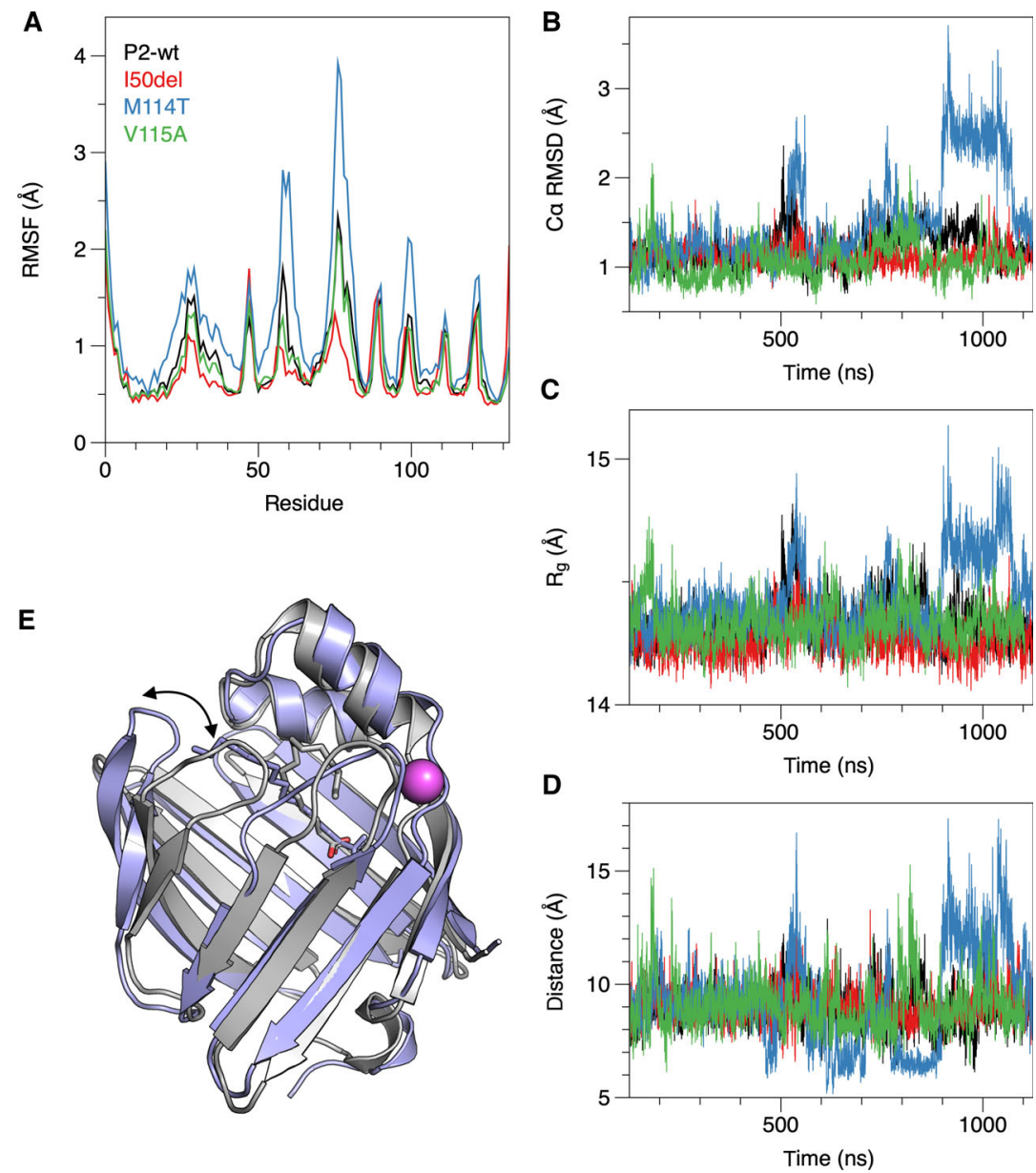

structure (Fig. 7D). The result is similar to that observed with the other CMT-linked variants of P2 [24], which suggests similar molecular mechanisms for the different disease variants.

\section{Molecular functions of disease variants}

One of the suggested main functions of P2 in PNS myelin is to glue stacked lipid bilayers together. To investigate the membrane stacking ability of $\mathrm{P} 2$ variants, they were subjected to a lipid vesicle aggregation assay (Fig. 8A), in which the vesicle aggregation induced by P2 is monitored as a change in a solution turbidity. Negatively charged model membrane systems of 1,2dimyristoyl-sn-glycero-3-phosphocholine (DMPC): 1,2dimyristoyl-sn-glycero-3-phosphorylglycerol (DMPG) vesicles were used. No significant differences were observed in turbidity between P2-wt and mutants. All variants gave the strongest signal at $10 \mu \mathrm{M}$, which corresponds to a molar $\mathrm{P} / \mathrm{L}$ ratio of $1: 50$. While one can expect highest stacking activity when each membrane surface is $50 \%$ or less saturated, it is likely that higher protein concentrations will saturate individual membranes and prevent stacking.

11-Dansylaminoundecanoid acid (DAUDA) is an environment-sensitive fluorescent fatty acid derivative probe, whose fluorescence emission spectrum changes upon interaction with a protein. No clear difference was seen in the spectrum of I50del compared to P2-wt (Fig. 8B,C). In contrast to I50del, both M114T and V115A showed a change in the fluorescence peak intensity at $535 \mathrm{~nm}$ compared to P2-wt (Fig. 8C). The fluorescence intensity of DAUDA with M114T and V115A increased, indicating enhanced binding of the fatty acid probe to these variants. This can be an indication of increased protein dynamics coupled to less saturation with bound E. coli fatty acids, originating from the expression system, in the mutant protein preparation, being reminiscent of previously studied P2 variants $[7,24,26,30]$. 

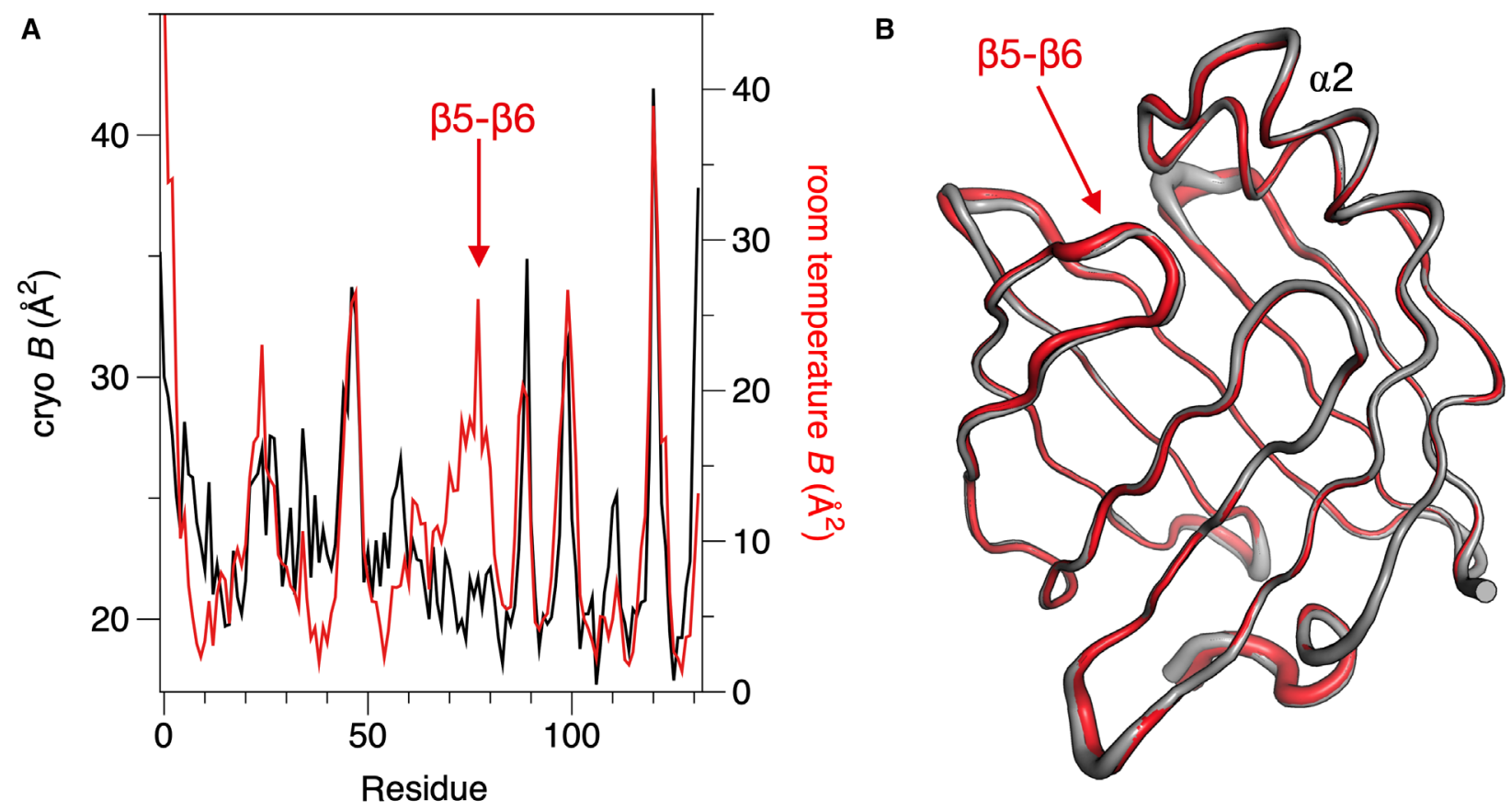

C

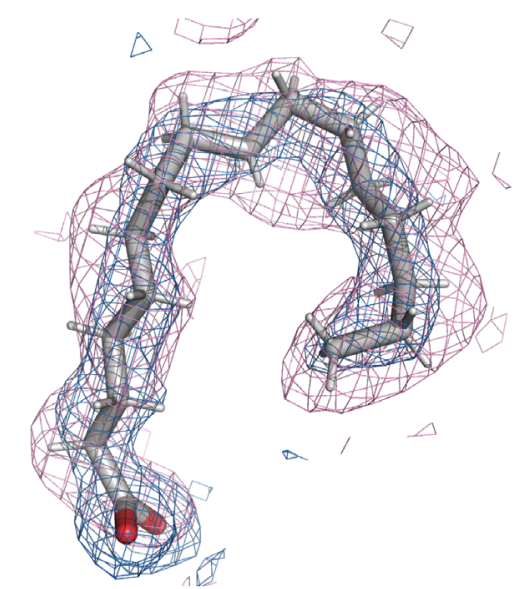

Palmitate
D

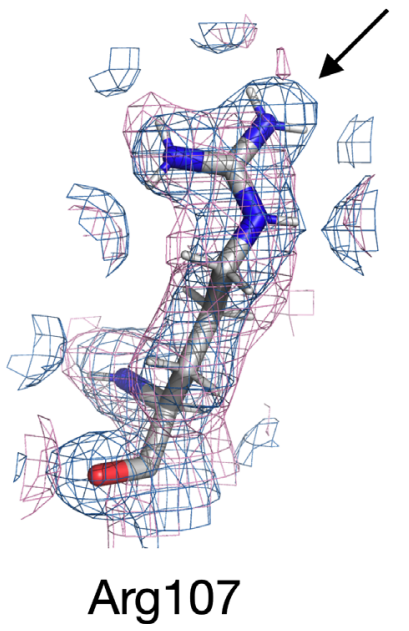

E

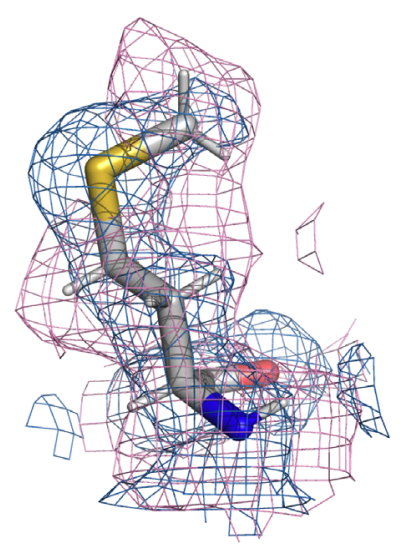

Met114

Fig. 6. $B$ factor-based analysis of dynamics in the crystal state. (A) Average B factor plot of human P2 at $100 \mathrm{~K}$ (black) and at RT (red). (B) Overlay of the cryo (grey) and RT (red) structures, with the thickness of the ribbon reflecting the B factor. (C-E) Electron (blue) and nuclear (pink) density maps of selected regions of the structure. The $2 F_{0}-F_{c}$ maps are both contoured at $1 \sigma$. The arrow in $D$ indicates lack of nuclear density for a part of the Arg107 guanidinium group. Arg107 was previously shown $[7,29]$ to be deprotonated in cryocooled crystals using ultrahigh-resolution X-ray crystallography. Structures rendered using PyMOL.

\section{Myelin protein P2 induces formation of double- membrane structures}

Time-lapse fluorescence microscopy was employed to explore the effects of human P2 (P2-wt, P2-M114T, P2I50del and P2-V115A) on planar double-supported membrane patches. An illustration of the structure of a double-supported membrane patch is shown on the top of Fig. 9. The isolated bilayer patches with free edges typically have diameters in the range of $50-100 \mu \mathrm{m}$. The model membrane composition was 90\% 1,2-dioleoyl-snglycero-3-phosphocholine (DOPC) and 10\% $1,2-$ dioleoyl-sn-glycero-3-phospho-L-serine (DOPS); and the membranes were hydrated in $10 \mathrm{~mm}$ Tris buffer with $2 \mathrm{mM} \mathrm{Ca}^{2+}$. Myelin P2 proteins were added to the fluid 

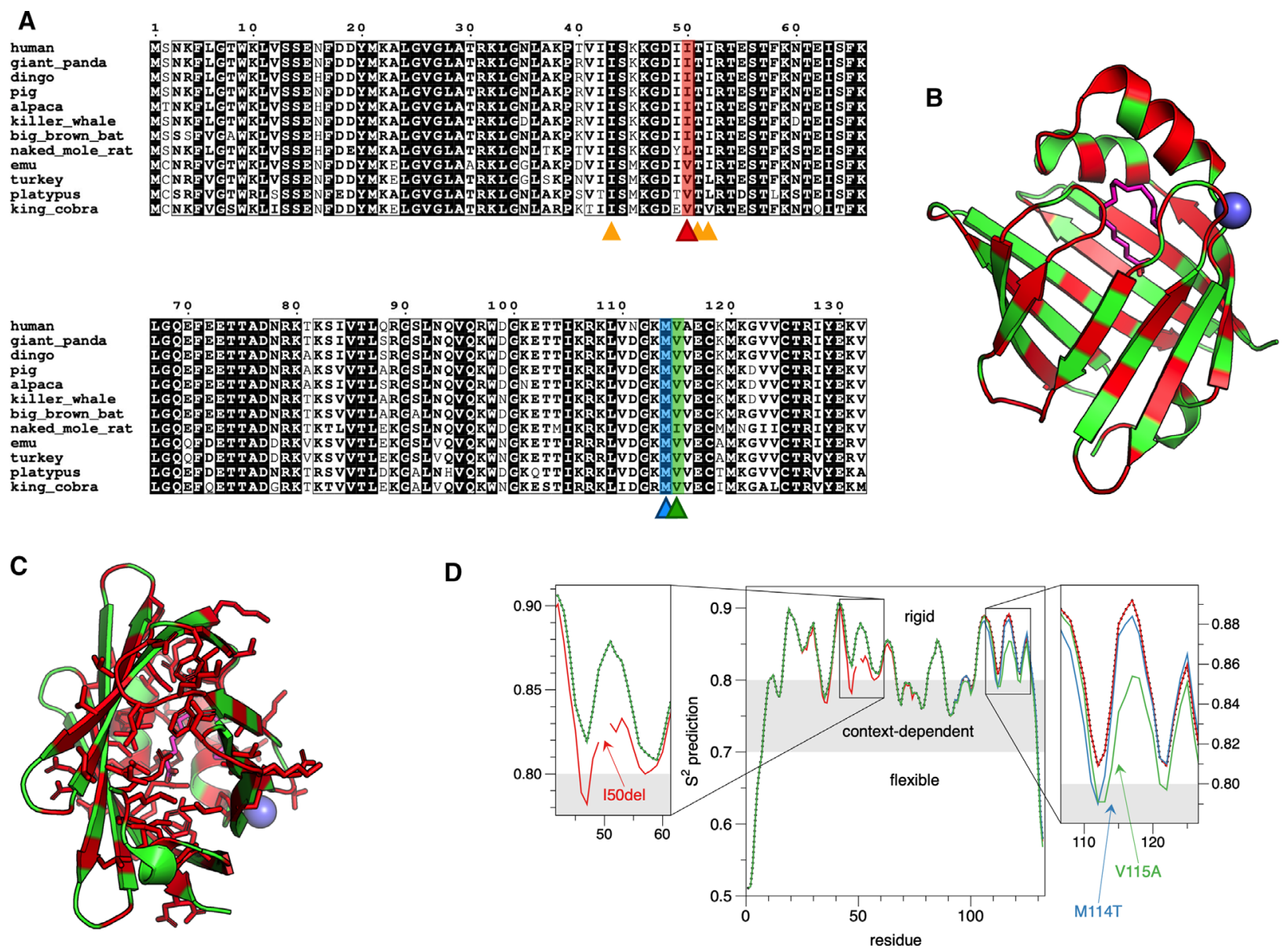

Fig. 7. Conservation mapped onto structure. (A) Sequence alignment of $P 2$ from 12 selected vertebrates. Fully conserved residues are shaded on black background. The positions of CMT mutations are highlighted as follows: previously studied mutations 143N, T51P, 152T: orange triangles; 150del: red triangle and shading; M114T: blue triangle and shading; V115A: green triangle and shading. (B) Mapping of the fully conserved residues (red) onto the P2 structure. The sphere indicates the anion-binding site and the hinge region, and the palmitate inside the $\beta$ barrel is shown as sticks. (C) View from the $\beta$ barrel bottom shows how the side chains of conserved residues in the barrel mainly point inwards. (D) Sequence-based dynamics prediction suggests that all CMT mutations increase local flexibility. Structures rendered using PyMOL.

cell from a concentrated solution to a final bulk concentration of $33.3 \mu \mathrm{m}$ in the cell. After addition, the proteins reach the membrane patch on a timescale of 30-60 s.

After exposure to P2-wt, membrane structures were observed to emerge from the membrane surface as viewed in Fig. 9A-D. Based on the fluorescence intensity in the images, these membrane structures have a higher intensity compared to a single-membrane patch, indicating a double membrane. These observations resemble structures from previous studies [31]. The double-membrane structures emerge after $\sim 2 \mathrm{~min}$, primarily at the edges of the double-supported membrane patch and continue to grow until $\sim 20 \mathrm{~min}$.

For comparison, we studied the effects induced by three P2 mutants; the results are shown in Fig. 9E-H (P2-M114T), Fig. 9I-L (P2-I50del) and Fig. 9M-P
(P2-V115A). Time-lapse videos of the experiment are additionally available as Movies S1, S2, S3 and S4. The P2 mutants primarily induced a large number of smaller membrane structures, mainly emerging from within the double-supported membrane patch, and not at the edges as observed for P2-wt. The small membrane structures are initiated on a similar timescale as observed for the larger planar structures induced by P2-wt. That is, the membrane effects induced by the P2 mutants are different and smaller, but they occur on a similar timescale as $\mathrm{P} 2-\mathrm{wt}$.

\section{Discussion}

P2 is a major component of PNS compact myelin $[32,33]$ and plays a role in lipid homeostasis of 



Fig. 8. Binding to membranes and fatty acid ligands. (A) Turbidimetric analysis of DMPC:DMPG lipid vesicle aggregation induced by P2 variants. The figure shows the average of three measurements. (B) Fluorescence spectra of DAUDA in the presence of $10 \mu \mathrm{M}$ P2. $\mathrm{C}$. Titration of DAUDA with P2, fluorescence measured at $535 \mathrm{~nm}$. All points were measured in triplicate.

Schwann cells and in peripheral myelin remodelling $[6,9]$. P2 mutations are inherited in an autosomal dominant manner and lead to demyelinating CMT1 with varying severity [14-17]. Recently, three novel CMT1associated P2 mutations (I50del, M114T and V115A) were discovered [27,28], but no experimental data on the structure or biophysical and biochemical characteristics of the corresponding protein products have been available. Our work provides new details of P2 function and may help to elucidate its function in myelin maintenance and remyelination as well as shed light on molecular mechanisms of CMT.

\section{Disease variants show reduced thermal stability despite similar structure}

P2 has a compact and stable $\beta$-barrel structure similar to other members of the FABP family. All residues currently known to be affected by disease mutations are conserved among most mammalian species. Nevertheless, none of the new mutations had major effects on the crystal structure of P2. Similar results were obtained earlier with the P2 I43N, T51P and I52T disease variants [26].

Since crystallization may favour the most stable conformation and hide functionally relevant differences, the structures of P2 variants were studied in solution. SAXS analysis revealed no differences in conformation, indicating correct folding and a closed $\beta$ barrel of the variants in solution. Hence, all variants studied here closely resemble the crystal structure in solution. Previously, we observed an altered X-ray scattering pattern and a more open conformation of the T51P disease variant in solution, which was linked to its reduced thermal stability and altered ligand-binding properties [26]. The only variant studied here that approached the $\mathrm{R}_{\mathrm{g}}$ of T51P occasionally in the simulation was M114T, reflecting its opening and closing.
The systematic difference between $\mathrm{R}_{\mathrm{g}}$ from SAXS and MD most likely relates to the fact that ordered solvent around the protein will affect $R_{\mathrm{g}}$ measured by SAXS, while it was not taken into account in calculating $R_{g}$ from the simulations. Differing solution dynamics may further be linked to both fatty acid ligand binding and membrane bilayer stacking.

The most drastic consequence of the $\mathrm{P} 2$ disease mutations studied here was observed in the thermal stability of the variants. Similarly, all previously studied CMT1-associated mutations showed 13-24 degrees reduced thermal stability compared to P2-wt, T51P being the most unstable [26]. I50del and M114T had 15 and 12 degrees lower thermal stability indicating the $T_{m}$ change in the same range with the earlier studied I43N and I52T variants [26]. V115A had a smaller effect on protein thermal stability; however, a drop in $T_{m}$ of several degrees corresponds to a large energetic difference, which is surprising considering the kind and location of this mutation on the outside of the barrel. Interestingly, the family carrying the V115A mutation did not show NCVs typical for CMT1 patients and suffered milder symptoms compared to patients with other P2 mutations [27]. This link between P2 stability and clinical features of the CMT1 patients is an important topic for future research; at the protein level, this could be studied, for example, using differential scanning calorimetry and computational techniques.

\section{Fatty acid and membrane bilayer binding}

P2 binds to lipid membranes using two opposite faces of the protein, leading to membrane stacking and formation of multilayered myelin-like assemblies [5,7,8,34]. Additionally, P2 binds and transports fatty acids into and from lipid membranes [6]. Here, we observed an enhanced binding of both point mutant 

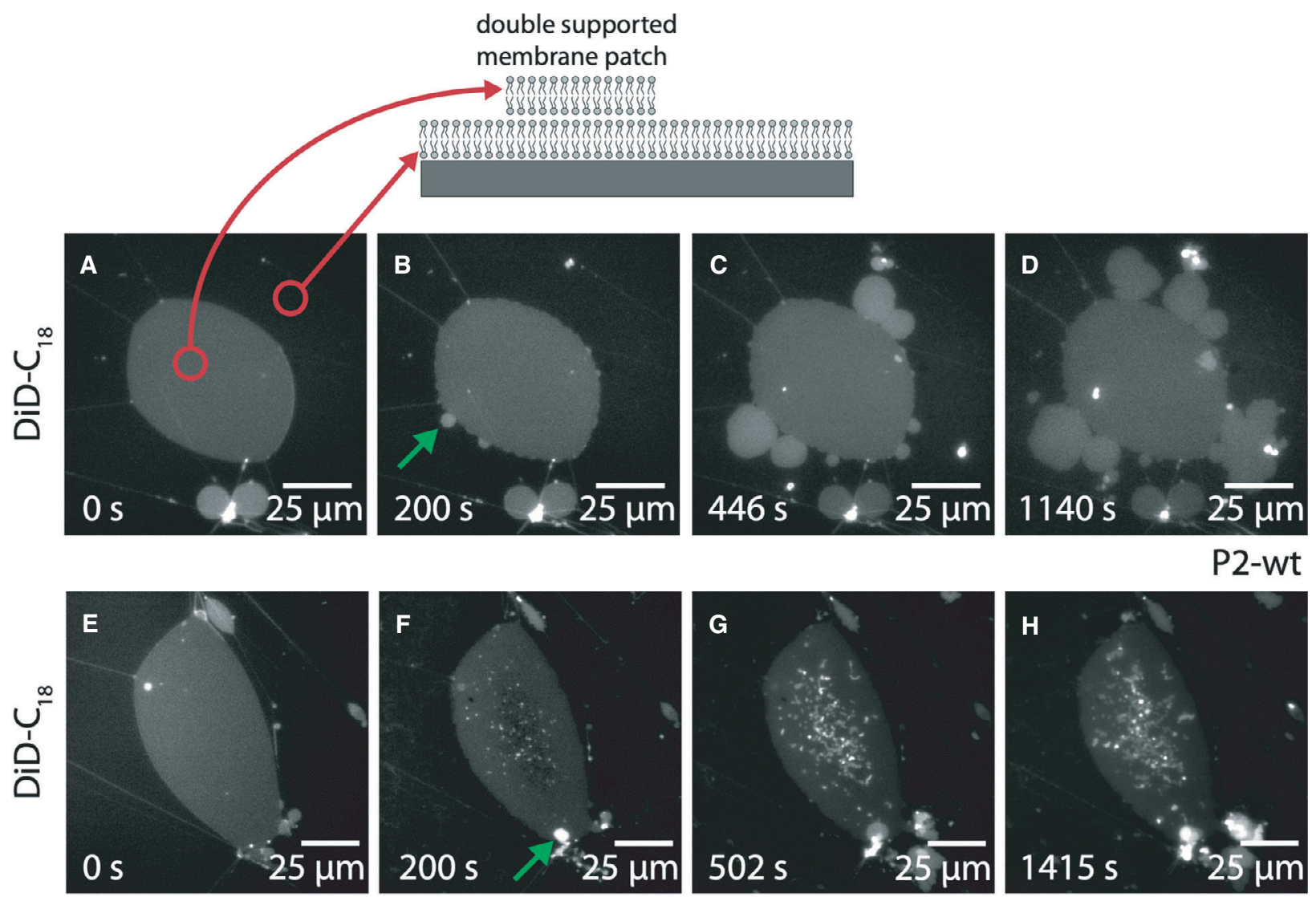

P2-M114T
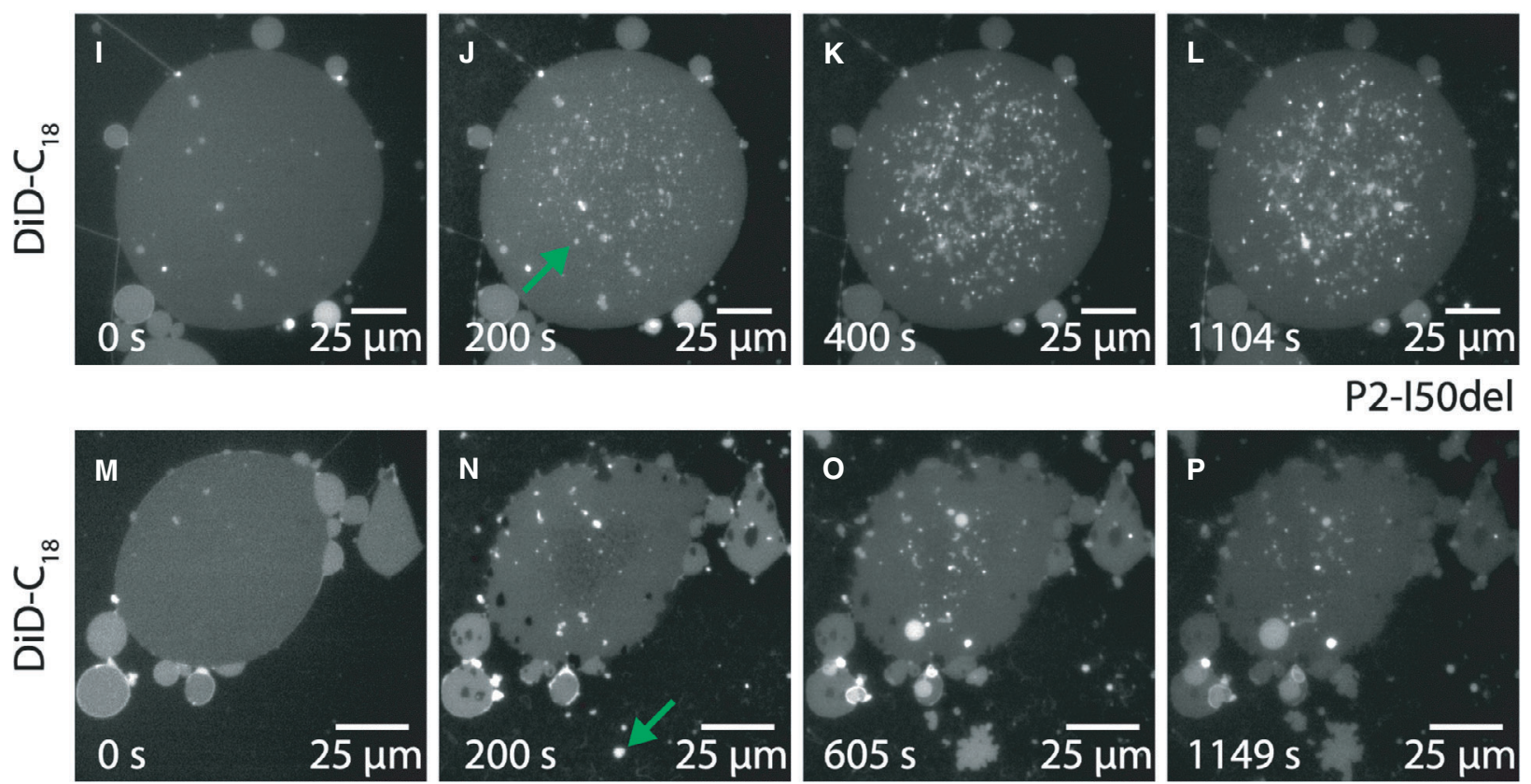

P2-V115A 
Fig. 9. Time-lapse fluorescence sequences showing formation of membrane structures induced by myelin protein $P 2$. Schematic of a double-supported model membrane patch (top). P2-wt induces formation of considerable double-membrane structures mainly initiated at the edges of the double-supported membrane patch (A-D). Upon exposure to P2 mutants P2-M114T (E-H), P2-I50del (I-L) and P2-V115A (M-P), a significant amount of primarily smaller membrane structures emerges from the membrane patch. The green arrows mark examples of formation of membrane structures. All proteins were at $33.3 \mu \mathrm{M}$ concentration. $N=4$ repetitions. Scale bar, $\underline{25 \mu \mathrm{m}}$.

variants to DAUDA, whereas I50del had no effect. These results resemble the ones obtained earlier with I43N and I52T mutants [26] and may indicate changes in fatty acid binding dynamics, which could influence lipid metabolism of Schwann cells and myelin membrane lipid composition. On the other hand, we did not observe any changes in lipid vesicle aggregation/ membrane stacking properties of the disease variants. The results are compatible with a scenario, in which the recombinant P2 variants are correctly folded, but dynamics of the barrel opening and portal region are altered, which may be coupled to less fatty acid binding in the mutant protein preparations-leading to apparently higher fatty acid binding in vitro.

Myelin protein P2 binds to membranes and induces spontaneous stacking into multilayers [7,8,34]. Furthermore, in these complexes, both the $\mathrm{P} 2$ protein and the lipids become less dynamic, indicating a synergistic stabilization of protein-lipid multilayers induced by the presence of $\mathrm{P} 2$ [7,8,34,35]. In time-lapse experiments on membranes, all P2 variants induced formation of new membrane structures. However, while the timescales were similar, all three CMT variants induced morphologically different membrane effects, whereby smaller membrane structures emerged upwards from the membrane plane. P2-wt induced larger, apparently flat, double-membrane structures at the edges of the bilayer island. The formation of additional membrane layers found in this study is in line with previous results on membrane stacking [5]. These functional aspects are central in beginning to understand the role myelin proteins play in myelin-like membrane stacking. Myelin is curved around the axon, and how these observations are linked to the curvature of the myelin membrane, and vice versa, remains a subject of future research.

In an earlier study, annexin A1 and annexin A2 both induced formation of double-membrane structures on a timescale of $<1 \mathrm{~min}$ [31], and they-much like myelin proteins - bind membrane surfaces together [36]. In comparison, the timescale of P2-induced formation of double membranes is somewhat slower, as the effect is initiated $\sim 2$ min after the protein has reached the membrane patch. For P2-wt, the total area of the emerging double-membrane structures is qualitatively similar to the effect reported for the annexins [31], while the large number of smaller membrane structures induced by the P2 mutants has not previously been observed in such assays. Given the somewhat different membrane morphologies, the mutated P2 variants may function differently from P2wt between two membranes and in the presence of the other PNS major dense line proteins $\mathrm{MBP}$ and $\mathrm{P} 0-\mathrm{a}$ system that is very challenging to study in vitro.

\section{Comparison to previously characterized P2 variants}

Our work complements structure/function studies of currently known CMT-associated mutations in the PMP2 gene. Table 3 presents an overview of the main points of current and earlier results on these variants at the protein level. While some of the mutations cause more severe impairment in the protein properties, they essentially all behave similarly. All P2 disease mutations cause a large decrease in protein thermal stability, and most of them affect dynamics and fatty acid binding. Not all have an effect on membrane stacking based on turbidimetric assays, and the work in this study shows that the mutations do not inhibit membrane morphological changes caused by $\mathrm{P} 2$.

Some correlations can be observed between disease severity in patients and the biophysical properties of the individual mutant proteins (Table 3). The thermal stability of V115A is affected much less than for the other mutants; patients having this variant have a very mild disease, with nearly normal NCVs [27]. On the other hand, M114T is one of the more structurally drastic mutations, having a nonconservative replacement of a buried side chain. The patients with M114T present severe demyelination [27]. T51P is the most unstable P2 mutant protein characterized, which can structurally be explained by the insertion of a Pro residue into a $\beta$ strand [26]. Patients with T51P have severe drop in NCV, coupled to muscle weakness and atrophy [16]. While these observations may hint towards more details of disease mechanisms, at the moment they must be treated as possible correlations. Similar apparent correlations between mutant protein properties and CMT disease phenotype were 
previously observed for the cytoplasmic tail of myelin protein $\mathrm{P} 0$ [37], which lies in the same compartment in the PNS myelin major dense line as P2. The fact that the thus-far observed CMT mutations in P2 cluster to the same 3D region may suggest a mutation hotspot carrying residues important for P2 structure or function.

Other mutations have been introduced into P2 over the years for structural and functional studies. Three of the most interesting ones include L28D, P39G and F58A [7,8,24,30]. Leu28 localizes at the tip of the $\alpha$ helical lid. In a cellular system, the L28D mutation inhibits the formation of cytoplasmic membrane domains observed with P2-wt, as well as revokes the increased melanoma cell invasion induced by $\mathrm{P} 2-\mathrm{wt}$ overexpression [7,11]. Additionally, in silico modelling predicts the embedding of Leu28 deep into the lipid bilayer during membrane interaction [7]. Pro39 is found in the hinge region of the lid and P39G is a generally more active $\mathrm{P} 2$ variant in all experiments, such as membrane stacking, fatty acid binding and dynamic analyses [24]. Phe58 is located in the portal region of $\mathrm{P} 2$ and is involved in the control of the opening of the $\beta$ barrel structure and membrane binding. This portal Phe residue is conserved in most FABPs and has a crucial role in FABP ligand binding and lipid transport [7,24,38]. In case of the mutations affecting directly fatty acid-binding residues (R107E, R127E and $\mathrm{Y} 129 \mathrm{~F}$ ), neither mutated proteins nor effects on cell viability were detected [11].

\section{Insights into structural dynamics in P2}

Conformational changes are likely to be central to the function of P2, both in lipid transport and in membrane stacking. The dynamics of the portal region are important in the entire FABP family, allowing for ligand entry and egress $[39,40]$. The division of the FABPs into two groups based on lipid transport mechanisms [41,42] gives further insight into the role of the portal region. $\mathrm{P} 2$ is a FABP with a collisional ligand transfer mechanism.

A common property of all disease mutant variants of human P2 is the decreased thermal stability of the fold; this may then lead to abnormal fatty acid and lipid bilayer binding. This trend is continued with the mutations studied here. The identified disease variants of P2 localize to two small clusters in the 3D structure, on opposite sides of the $\beta$ barrel structure (Fig. 1). The location could be a sign of a hotspot for correct folding and/or functional dynamics related to membrane and lipid ligand binding. The mutations are far from the portal region, but $\mathrm{P} 2$ being a small protein, altering the dynamics and flexibility of one end of the $\beta$ barrel could well have large effects on the opening of the portal region at the other end. Simulations close to lipid membrane surfaces would give additional information on functional dynamics of the P2 mutants. The fact that membrane stacking properties are not much affected by the mutations indicates the surface properties of the mutant variants per se are similar.

For an insight into human P2 dynamics, we combined MD simulations with RT crystallography. The crystal structure at RT, compared to the structure at $100 \mathrm{~K}$, has high $\mathrm{B}$ factors in the $\beta 5-\beta 6$ loop, which is the most mobile part of $\mathrm{P} 2$, when the $\beta$ barrel opens up. Simulations have reproducibly indicated this opening $[24,26,30]$, and we could detect it for the earlier studied P2 CMT variants in solution using synchrotron SAXS [26]. Hence, functionally relevant dynamics can be revealed by RT crystallography in comparison to cryocooled crystals.

\section{What is the function of $P 2$ in humans?}

Historically, P2 was characterized as an abundant component of the PNS myelin sheath; intriguingly, it is not present in all myelin sheaths, however [33], and the amount of P2 varies between species [43,44]. P2deficient mice had a very mild phenotype, with effects on lipid homeostasis in the PNS at periods of active myelination [6]. The mutant mice also indicated a role for P2 in mouse PNS remyelination [9]. The identification of several $P M P 2$ point mutations in recent years in CMT families [14-17,27,28] has shed more light on P2 as being important for the correct formation and maintenance of human PNS myelin. All these conclusions have been based on the assumption that $\mathrm{P} 2$ is more or less specific to myelinating PNS Schwann cells in vertebrates in general, and even more so in mammals.

Recently, several studies have highlighted strong expression of P2 in human astrocytes, while $\mathrm{P} 2$ is essentially missing in mouse astrocytes [2,10]. This observation has been linked to the size regulation of astrocytes, and expression of P2 in mouse astrocytes increased their size [2]. These results have implications for understanding the function of $\mathrm{P} 2$; mouse models will not be informative in relation to its function in human astrocytes.

Furthermore, as human PNS myelin is much thicker than that of mice, mouse models may not give a complete view of human P2 function even in PNS Schwann cells, given the difference in lifespan and the requirements this brings to proteins in stable biostructures, such as the myelin sheath. Myelin proteins are 
among the most long-lived proteins in vertebrates $[45,46]$. These are important pointers towards critical analysis of mouse models in general-in this case for a single, apparently rather mundane but stable protein, which could have more widespread implications. In other words, P2 may be more important for humans, and possibly other large vertebrates, than small mammals, such as the mouse. This importance of P2 is not necessarily restricted to PNS myelin, and it may extend to CNS astrocytes.

\section{Conclusions}

In current and earlier work, we have shown that the CMT-associated variants of human P2 have similar properties to each other. While crystal structures of all disease variants are nearly identical to P2-wt, with minor differences in local hydrogen bonding, the thermal stability of the variants in solution and their function in lipid binding are affected. As P2 has been thought to function in both lipid transport and membrane multilayer stacking, different functional aspects could be affected by these properties. A functional, stable P2 could be more important in humans than in mouse models, and in addition to the importance of unravelling the role of $\mathrm{P} 2$ in human PNS myelin, the molecular function of $\mathrm{P} 2$ in human astrocytes, large cells with strong membrane synthesis, deserves further study.

\section{Materials and methods}

\section{Mutagenesis}

A construct containing human P2 with an N-terminal Histag and a tobacco etch virus (TEV) protease cleavage site cloned into the pTH27 vector [4] was used to express P2-wt and as a template plasmid in mutagenesis to produce the I50del, M114T and V115A variants. Primers to generate P2 mutations were purchased from Eurofins Genomics (Ebersberg, Germany; Table S1). Mutagenesis was carried out using the QuikChange Site-Directed Mutagenesis protocol (Agilent Technologies, Santa Clara, CA, USA) and Phusion ${ }^{\circledR}$ High-Fidelity DNA Polymerase (New England Biolabs, Ipswich, MA, USA). Constructs were validated by DNA sequencing analysis.

\section{Protein expression}

Proteins were expressed in E. coli Rosetta (DE3) strain in ZYM-5052 autoinduction medium with $100 \mu \mathrm{g} \cdot \mathrm{mL}^{-1}$ of ampicillin at $+18{ }^{\circ} \mathrm{C}$ for $44 \mathrm{~h} \mathrm{[47]}$. The cells were harvested and suspended in a lysis buffer $(300 \mathrm{~mm} \mathrm{NaCl}, 10 \mathrm{~mm}$ imidazole, 50 mм HEPES pH 7.5, 1 mм DTT).

\section{Protein purification}

For protein purification, cells were lysed by sonication and insoluble materials were pelleted by centrifugation (51000 $\mathrm{x} g, 30 \mathrm{~min}$, at $+4{ }^{\circ} \mathrm{C}$ ). The soluble fraction was mixed with the HisPur Ni-NTA Resin (Thermo Fisher Scientific Inc., Waltham, MA, USA) at $+4{ }^{\circ} \mathrm{C}$ for $2 \mathrm{~h}$. The resin was washed two times with washing buffer $(300 \mathrm{~mm} \mathrm{NaCl}$, $40 \mathrm{~mm}$ imidazole, $50 \mathrm{~mm}$ HEPES $\mathrm{pH} 7.5,1 \mathrm{~mm}$ DTT) using centrifugation $\left(300 \times \mathrm{g}, 4 \mathrm{~min}\right.$, at $\left.+4{ }^{\circ} \mathrm{C}\right)$. Then, the samples were transferred into a gravity-flow column and further washed with $100 \mathrm{~mL}$ of washing buffer. The samples were incubated for $5 \mathrm{~min}$ and eluted with elution buffer (300 mм NaCl, $300 \mathrm{~mm}$ imidazole, $50 \mathrm{~mm}$ HEPES pH $7.5,1 \mathrm{~mm}$ DTT). To cleave the His-tag, $40 \mu \mathrm{M}$ of recombinant TEV protease was added. Imidazole was removed by dialysis through Spectra/Por, 6-8 kDa MWCO dialysis tubing (Spectrum Labs, San Francisco, CA, USA) against dialysis buffer $(300 \mathrm{~mm} \mathrm{NaCl}, 20 \mathrm{~mm}$ HEPES $\mathrm{pH} 7.5$ and $1 \mathrm{~mm}$ DTT) at $+4{ }^{\circ} \mathrm{C}$ for $17 \mathrm{~h}$. TEV and the cleaved Histag were removed with a reverse immobilized metal affinity chromatography step using the HisPur Ni-NTA and the dialysis buffer. Proteins were further purified with sizeexclusion chromatography (SEC) using the dialysis buffer and a Superdex 75 pg 16/600 column (GE Healthcare, Chicago, IL, USA). The proteins were concentrated with Amicon Ultra 15, MWCO $10 \mathrm{kDA}$ protein concentrator (Merck KGaA, Darmstadt, Germany) to the final concentration of $9-10 \mathrm{mg} \cdot \mathrm{mL}^{-1}$.

\section{Crystallization and structure determination}

P2 mutants were crystallized at $+20{ }^{\circ} \mathrm{C}$ using the sitting drop vapour diffusion method. The concentrations of the I50del, M114T and V115A mutants were 9.5, 9.5 and $10 \mathrm{mg} \cdot \mathrm{mL}^{-1}$, respectively. M114T was crystallized in $2.4 \mathrm{M}$ sodium malonate, $\mathrm{pH}$ 7.0. I50del was crystallized in $1.9 \mathrm{M}$ sodium malonate, $\mathrm{pH} 6.4$. V115A was crystallized in $2.2 \mathrm{M}$ sodium malonate, $\mathrm{pH}$ 7.19. Diffraction data were collected on beamlines P11 [48] and P13 [49] at PETRA III, DESY (Hamburg, Germany). Data were processed using XDS [50]. The crystal structures were solved by molecular replacement using the wild-type human P2 structure (PDB entries 3NR3 or 4BVM) [7] as a search model in Phaser [51]. The structures were refined and built using phenix.refine [52] and Coot [53]. MolProbity [54] was used for structure validation.

\section{Structure of perdeuterated P2 at RT}

Human P2 perdeuteration, purification and crystallization have been described before [55]. Crystallization involved feeding with fresh protein over a period of 10 months to obtain large crystal volumes of $0.3 \mathrm{~mm}^{3}$. Neutron data collection and processing have been described [55]. X-ray 
diffraction data were collected from another perdeuterated P2 crystal from the same batch on a GeniX $\mathrm{Cu}$ HF rotating anode instrument, and the data were processed with XDS. Joint X-ray/neutron refinement was carried out in phenix.refine and rebuilding in Coot.

\section{SAXS combined with size-exclusion chromatography}

Small-angle X-ray scattering combined with size-exclusion chromatography (SEC-SAXS) data were collected on B21 beamline Diamond Light Source (Chilton, Oxfordshire, UK) [56]. The concentrations of P2-wt, P2-I50del, P2-M114T and P2-V115A were 9.9, 9.6, 10.5 and $8.9 \mathrm{mg} \cdot \mathrm{mL}^{-1}$, respectively. The proteins were run in a buffer containing $300 \mathrm{~mm} \mathrm{NaCl}$, $20 \mathrm{~mm}$ HEPES pH 7.5, $1 \mathrm{~mm}$ DTT (dialysis buffer from above) on a Superdex 200 Increase 3.2 column (GE Healthcare), while SAXS data were continuously collected from the eluate. Scattering of the buffer was subtracted from the scattering within the eluted protein peak. The data were analysed with the ATSAS package [57] and dummy atom models built with DAMMIN [58]. The data and models were deposited at SASBDB [59], with the accession codes SASDLA5 (P2-wt), SASDLB5 (i50del), SASDLC5 (M114T) and SASDLD5 (V115A).

\section{Circular dichroism spectroscopy}

For CD measurements, the protein samples were dialysed with 500-1000 Da Thermo Scientific ${ }^{\mathrm{TM}}$ Slide-A-Lyzer ${ }^{\mathrm{TM}}$ MINI Dialysis Devices into buffer containing $10 \mathrm{~mm}$ sodium phosphate, $\mathrm{pH}$ 7.7. The proteins were diluted to a final concentration of $50 \mu \mathrm{g} \cdot \mathrm{mL}^{-1}$. CD spectra were collected using Hellma quartz cuvettes with a $1.0-\mathrm{mm}$ path length between 190 and $280 \mathrm{~nm}$. For thermal scans, a ramping rate of $1{ }^{\circ} \mathrm{C} \cdot \mathrm{min}^{-1}$ between $+22-94{ }^{\circ} \mathrm{C}$ was used. Experiments were done with the Chirascan ${ }^{\mathrm{TM}}$ CD Spectrometer (Applied Photophysics Ltd, Leatherhead, Surrey, UK). Global 3 (Applied Photophysics Ltd) was used to calculate melting temperatures.

\section{Lipid vesicle aggregation assay}

To study vesicle aggregation, a protein concentration series $(0,2.5,5,10$ and $20 \mu \mathrm{M})$ was mixed with $0.5 \mathrm{~mm}$ unilamellar vesicles (DMPC:DMPG 1: 1; Avanti Polar Lipids, Inc., Alabama, USA) containing a 1:1 molar ratio of DMPC:DMPG, in HBS buffer (150 mM NaCl, $20 \mathrm{~mm}$ HEPES $\mathrm{pH}$ 7.5). A Tecan Infinite M1000 Pro plate reader was used to measure the absorbance, shaking before each measurement. The temperature was set at $+30{ }^{\circ} \mathrm{C}$ and the wavelength at $450 \mathrm{~nm}$. Six measurements every 5 min were done in triplicates. The data were plotted with GRAPHPAD PRISM 8 (GraphPad Software Inc., San Diego, CA, USA).

\section{DAUDA binding assay}

A fluorescent fatty acid analog, DAUDA, was used to study fatty acid binding to $\mathrm{P} 2$. The proteins were diluted into HBS. Protein concentrations of $0,1,2.5,5,10$ and $20 \mu \mathrm{M}$ were used with $10 \mu \mathrm{M}$ DAUDA. The fluorescence emission spectra $(400-700 \mathrm{~nm})$ with excitation at $345 \mathrm{~nm}$ were measured with the Tecan Infinite M1000 Pro plate reader. The data were visualized and analysed with GRAPHPAD PRISM 8.

\section{Bioinformatics}

Sequences were aligned using ClustalW [60] and ESPript [61]. Sequence-based predictions of protein flexibility were done using DynaMine [62].

\section{MD simulations}

The crystal structures of P2-wt and the disease variants, including a bound palmitate molecule, were used as starting points for MD simulations in YASARA, as previously described [63]. The AMBER14 force field [64] with the explicit TIP3P solvent model was used, and pressure and temperature were controlled with the YASARA densostat [65]. The simulated systems were built in a dodecahedral cell, with a physiological ionic strength of $0.15 \mathrm{M} \mathrm{NaCl}$. After energy minimization, MD simulations were run for at least $1100 \mathrm{~ns}$ each, at $+25^{\circ} \mathrm{C}$, and further trajectory analysis was done using YASARA. The first 500 snapshots (125 ns) of each simulation were taken as the equilibration period, based on lack of major fluctuations in $R_{g}$ or RMSD values before that point. Thereafter, 1000 ns of the simulation were included in the analysis in all cases.

\section{Double-supported model membrane patches and time-lapse fluorescence microscopy}

Hydrated double-supported model membrane patches were prepared using the spin coating technique following the method previously described $[31,66]$. Briefly, planar mica substrates were glued on glass coverslips, and prior to use, the mica was freshly cleaved. $30 \mu \mathrm{L}$ of a $10 \mathrm{~mm}$ lipid solution containing $90 \%$ DOPC, $10 \%$ DOPS and $0.5 \%$ DiD-C C $_{18}$ (1,1'-dioctadecyl-3,3,3',3'-tetramethylindodicarbocyanine, 4chloro-benzenesulfonate salt) was spin-coated at $3000 \mathrm{rpm}$ for $40 \mathrm{~s}$ leading to the formation of a dry lipid film. After $\sim 12 \mathrm{~h}$ in vacuum, the dry lipid film was placed in a liquid chamber and hydrated using a $10 \mathrm{~mm}$ Tris buffer (2-amino2-hydroxymethyl-propane-1,3-diol), $140 \mathrm{~mm} \mathrm{NaCl,} 2 \mathrm{~mm}$ $\mathrm{Ca}^{2+}, \mathrm{pH}=7.4$, at $+60{ }^{\circ} \mathrm{C}$ for $2 \mathrm{~h}$. The hydrated multilayered membrane was gently flushed with buffer to reduce the multilayers of the membrane to the desired structure of double-supported membrane patches. Next, the buffer was exchanged $\sim 10$ times to remove the excess of floating lipid 
fragments in the chamber. The samples were then equilibrated at RT for $1 \mathrm{~h}$, and the response of the membrane patches to the addition of protein was monitored with timelapse fluorescence microscopy.

For imaging, a Nikon ECLIPSE TE2000-U inverted fluorescence microscope (Nikon Corporation, Tokyo, Japan) was used. The setup includes a switchable monochromatic Xenon lamp (Polychrome V, Till Photonics GmbH, Grafelfing, Germany) for excitation, fitted with a custom filter cube for imaging at $640 \mathrm{~nm}$ (DiD). For all experiments, a $40 \times$ air objective (Nikon ELWD, NA $=0.60$, Plan Fluor and infinity corrected) was used. Images were recorded using a cooled EMCCD camera system (Sensicam em, $1004 \times 1002$ pixels, PCO-imaging, Kelheim, Germany). The recording was controlled with the associated LIVE ACQUISITION software (FEI GmbH, Hillsboro, OR, USA). Time-lapse videos were processed with FIJI (National Institutes of Health, Bethesda, MD, USA).

\section{Acknowledgements}

The use of the facilities and expertise of the Structural Biology and Proteomics and Protein Analysis core facilities, as well as the Sequencing Center at Biocenter Oulu, a member of Biocenter Finland, are gratefully acknowledged. We acknowledge DESY (Hamburg, Germany), a member of the Helmholtz Association HGF, for the provision of experimental facilities. Parts of this research were carried out at PETRA III, and we would like to thank beamline staff for assistance in using the P11 beamline. The synchrotron SAXS data were collected on beamline P12 operated by EMBL Hamburg at the PETRA III storage ring (DESY, Hamburg, Germany). We would also like to thank Diamond Light Source (Oxfordshire, United Kingdom) for SAXS beamline B21, and the staff of SAXS beamline B21 for assistance with testing and data collection. Beamtime at ILL is gratefully acknowledged. We acknowledge financial support from the Independent Research Fund Denmark (DFF-FNU), grant no. 7014-00036B (MBK, ACS), Biocenter Oulu (PK, SR, MU), Jane and Aatos Erkko Foundation (PK), and European Spallation Source (PK, $\mathrm{SL})$. The funding sources did not participate in carrying out the research or in the publication process.

\section{Conflict of interest}

The authors declare no conflict of interest.

\section{Author contributions}

MU, MBK, SL, MPB, ACS, SR and PK planned the experiments; MU, MBK, SL and MPB performed experiments; MU, MBK, MPB, ACS, SR and PK analysed data; SL, MPB and ACS contributed reagents or other essential material; and MU, MBK, SR and PK wrote the paper.

\section{Peer Review}

The peer review history for this article is available at https://publons.com/publon/10.1111/febs.16079.

\section{References}

1 Chmurzyńska A (2006) The multigene family of fatty acid-binding proteins (FABPs): function, structure and polymorphism. J Appl Genet 47, 39-48.

2 Kelley KW, Nakao-Inoue H, Molofsky AV \& Oldham MC (2018) Variation among intact tissue samples reveals the core transcriptional features of human CNS cell classes. Nat Neurosci 21, 1171-1184.

3 Gould RM, Oakley T, Goldstone JV, Dugas JC, Brady ST \& Gow A (2008) Myelin sheaths are formed with proteins that originated in vertebrate lineages. Neuron Glia Biol 4, 137-152.

4 Majava V, Polverini E, Mazzini A, Nanekar R, Knoll W, Peters J, Natali F, Baumgärtel P, Kursula I \& Kursula P (2010) Structural and Functional Characterization of Human Peripheral Nervous System Myelin Protein P2. PLoS ONE 5, e10300.

5 Suresh S, Wang C, Nanekar R, Kursula P \& Edwardson JM (2010) Myelin basic protein and myelin protein 2 act synergistically to cause stacking of lipid bilayers. Biochemistry 49, 3456-3463.

6 Zenker J, Stettner M, Ruskamo S, Domènech-Estévez E, Baloui H, Médard J-J, Verheijen MHG, Brouwers JF, Kursula P, Kieseier BC et al. (2014) A role of peripheral myelin protein 2 in lipid homeostasis of myelinating schwann cells: Pmp2 Function in the PNS. Glia 62, 1502-1512.

7 Ruskamo S, Yadav RP, Sharma S, Lehtimäki M, Laulumaa S, Aggarwal S, Simons M, Bürck J, Ulrich AS, Juffer AH et al. (2014) Atomic resolution view into the structure-function relationships of the human myelin peripheral membrane protein P2. Acta Crystallogr D 70, 165-176.

8 Ruskamo S, Krokengen OC, Kowal J, Nieminen T, Lehtimäki M, Raasakka A, Dandey VP, Vattulainen I, Stahlberg H \& Kursula P (2020) Cryo-EM, X-ray diffraction, and atomistic simulations reveal determinants for the formation of a supramolecular myelin-like proteolipid lattice. J Biol Chem 295, 86928705.

9 Stettner M, Zenker J, Klingler F, Szepanowski F, Hartung H-P, Mausberg AK, Kleinschnitz C, Chrast R $\&$ Kieseier BC (2018) The role of peripheral myelin 
protein 2 in remyelination. Cell Mol Neurobiol 38, 487496.

10 Cai Y, Zhong X, Wang Y \& Yang J (2015) Screening feature genes of astrocytoma using a combined method of microarray gene expression profiling and bioinformatics analysis. Int J Clin Exp Med 8, 18004 18012.

11 Graf SA, Heppt MV, Wessely A, Krebs S, Kammerbauer C, Hornig E, Strieder A, Blum H, Bosserhoff A-K \& Berking C (2019) The myelin protein PMP2 is regulated by SOX10 and drives melanoma cell invasion. Pigment Cell Melanoma Res 32, 424-434.

12 Ahn H-S, Yeom J, Yu J, Kwon Y-I, Kim J-H \& Kim K (2020) Convergence of plasma metabolomics and proteomics analysis to discover signatures of high-grade serous ovarian cancer. Cancers 12, 3447.

13 Chen B-J, Luo W-W, Zhao W-D, Qian X-Q, Wang Y-M, Zheng Y, Wang X-W, Xu X, Yuan Y-S, Chi F-L et al. (2021) The transcriptome characteristics of vestibular organs from delayed endolymphatic hydrops patients (Meniere's disease). Clin Otolaryngol 46, 823-833.

14 Gonzaga-Jauregui C, Harel T, Gambin T, Kousi M, Griffin LB, Francescatto L, Ozes B, Karaca E, Jhangiani SN, Bainbridge MN et al.(2015) Exome sequence analysis suggests that genetic burden contributes to phenotypic variability and complex neuropathy. Cell Rep 12, 1169-1183.

15 Hong YB, Joo J, Hyun YS, Kwak G, Choi Y-R, Yeo HK, Jwa DH, Kim EJ, Mo WM, Nam SH et al. (2016) A mutation in PMP2 causes dominant demyelinating charcot-marie-tooth neuropathy. PLoS Genet 12, e1005829.

16 Motley WW, Palaima P, Yum SW, Gonzalez MA, Tao F, Wanschitz JV, Strickland AV, Löscher WN, De Vriendt E, Koppi S et al. (2016) De novo PMP2 mutations in families with type 1 Charcot-Marie-Tooth disease. Brain 139, 1649-1656.

17 Punetha J, Mackay-Loder L, Harel T, Coban-Akdemir Z, Jhangiani SN, Gibbs RA, Lee I, Terespolsky D, Lupski JR \& Posey JE (2018) Identification of a pathogenic PMP2 variant in a multi-generational family with CMT type 1: Clinical gene panels versus genomewide approaches to molecular diagnosis. Mol Genet Metab 125, 302-304.

18 Morena J, Gupta A \& Hoyle JC (2019) Charcot-MarieTooth: from molecules to therapy. Int J Mol Sci 20, 3419.

19 Stavrou M, Sargiannidou I, Christofi T \& Kleopa KA (2021) Genetic mechanisms of peripheral nerve disease. Neurosci Lett 742, 135357.

20 Pareyson D, Saveri P \& Pisciotta C (2017) New developments in Charcot-Marie-Tooth neuropathy and related diseases. Curr Opin Neurol 30, 471-480.

21 Bird TD (2020) Charcot-Marie-Tooth (CMT) hereditary neuropathy overview. Eur J Hum Genet 17, 703-710.
22 Jones TA, Bergfors T, Sedzik J \& Unge T (1988) The three-dimensional structure of $\mathrm{P} 2$ myelin protein. The EMBO Journal 7, 1597-1604.

23 Hunter DJB, Macmaster R, Roszak AW, RiboldiTunnicliffe A, Griffiths IR \& Freer AA (2005) Structure of myelin P2 protein from equine spinal cord. Acta Crystallogr D 61, 1067-1071.

24 Laulumaa S, Nieminen T, Raasakka A, Krokengen OC, Safaryan A, Hallin EI, Brysbaert G, Lensink MF, Ruskamo S, Vattulainen I et al. (2018) Structure and dynamics of a human myelin protein $\mathrm{P} 2$ portal region mutant indicate opening of the $\beta$ barrel in fatty acid binding proteins. BMC Struct Biol 18, 8.

25 Lehtimäki M, Laulumaa S, Ruskamo S \& Kursula P (2012) Production and crystallization of a panel of structure-based mutants of the human myelin peripheral membrane protein P2. Acta Crystallogr F Struct Biol Cryst Commun 68, 1359-1362.

26 Ruskamo S, Nieminen T, Kristiansen CK, Vatne GH, Baumann A, Hallin EI, Raasakka A, Joensuu P, Bergmann U, Vattulainen I et al. (2017) Molecular mechanisms of Charcot-Marie-Tooth neuropathy linked to mutations in human myelin protein P2. Sci Rep 7, 6510.

27 Palaima P, Chamova T, Jander S, Mitev V, Van Broeckhoven C, Tournev I, Peeters K \& Jordanova A (2019) Peripheral myelin protein 2 - a novel cluster of mutations causing Charcot-Marie-Tooth neuropathy. Orphanet J Rare Dis 14, 197.

28 Geroldi A, Prada V, Veneri F, Trevisan L, Origone P, Grandis M, Schenone A, Gemelli C, Lanteri P, Fossa P et al. (2020) Early onset demyelinating Charcot-MarieTooth disease caused by a novel in-frame isoleucine deletion in peripheral myelin protein 2. J Peripher Nerv Syst 25, 102-106.

29 Laulumaa S \& Kursula P (2019) Sub-atomic resolution crystal structures reveal conserved geometric outliers at functional sites. Molecules 24, 3044.

30 Laulumaa S, Nieminen T, Lehtimäki M, Aggarwal S, Simons M, Koza MM, Vattulainen I, Kursula P \& Natali F (2015) Dynamics of the peripheral membrane protein $\mathrm{P} 2$ from human myelin measured by neutron scattering - a comparison between wild-type protein and a hinge mutant. PLOS ONE 10, e0128954.

31 Boye TL, Jeppesen JC, Maeda K, Pezeshkian W, Solovyeva V, Nylandsted J \& Simonsen AC (2018) Annexins induce curvature on free-edge membranes displaying distinct morphologies. Sci Rep 8, 10309.

32 Trapp BD, Dubois-Dalcq M \& Quarles RH (1984) Ultrastructural localization of P2 protein in actively myelinating rat Schwann cells. $J$ Neurochem 43, 944 948.

33 Trapp BD, McIntyre LJ, Quarles RH, Sternberger NH \& Webster HD (1979) Immunocytochemical localization of rat peripheral nervous system myelin 
proteins: $\mathrm{P} 2$ protein is not a component of all peripheral nervous system myelin sheaths. PNAS 76, 3552-3556.

34 Knoll W, Peters J, Kursula P, Gerelli Y, Ollivier J, Demé B, Telling M, Kemner E \& Natali F (2014) Structural and dynamical properties of reconstituted myelin sheaths in the presence of myelin proteins MBP and P2 studied by neutron scattering. Soft Matter 10, 519-529.

35 Knoll W, Natali F, Peters J, Nanekar R, Wang C \& Kursula P (2010) Dynamic properties of a reconstituted myelin sheath. Spectroscopy 24, 585-592.

36 Berg Klenow M, Iversen C, Wendelboe Lund F, Mularski A, Busk Heitmann AS, Dias C, Nylandsted J \& Simonsen AC (2021) Annexins A1 and A2 accumulate and are immobilized at cross-linked membrane-membrane interfaces. Biochemistry 60, 1248 1259.

37 Raasakka A, Ruskamo S, Barker R, Krokengen OC, Vatne GH, Kristiansen CK, Hallin EI, Skoda MWA, Bergmann U, Wacklin-Knecht $\mathrm{H}$ et al. (2019) Neuropathy-related mutations alter the membrane binding properties of the human myelin protein $\mathrm{P} 0$ cytoplasmic tail. PLoS ONE 14, e0216833.

38 Simpson MA \& Bernlohr DA (1998) Analysis of a series of phenylalanine 57 mutants of the adipocyte lipid-binding protein. Biochemistry 37, 10980-10986.

39 Friedman R, Nachliel E \& Gutman M (2006) Fatty acid binding proteins: same structure but different binding mechanisms? Molecular dynamics simulations of intestinal fatty acid binding protein. Biophys $J \mathbf{9 0}$, 1535-1545.

40 Ragona L, Pagano K, Tomaselli S, Favretto F, Ceccon A, Zanzoni S, D'Onofrio M, Assfalg M \& Molinari $\mathrm{H}$ (2014) The role of dynamics in modulating ligand exchange in intracellular lipid binding proteins. Biochim Biophys Acta 1844, 1268-1278.

41 Storch J (1993) Diversity of fatty acid-binding protein structure and function: studies with fluorescent ligands. Mol Cell Biochem 123, 45-53.

42 Thumser AE \& Storch J (2000) Liver and intestinal fatty acid-binding proteins obtain fatty acids from phospholipid membranes by different mechanisms. $J$ Lipid Res 41, 647-656.

43 Greenfield S, Brostoff S, Eylar EH \& Morell P (1973) Protein composition of myelin of the peripheral nervous system. J Neurochem 20, 1207-1216.

44 Singh H, Silberlicht I \& Singh IJ (1978) A comparative study of the polypeptides of mammalian peripheral nerve myelin. Brain Res 144, 303-311.

45 Fornasiero EF, Mandad S, Wildhagen H, Alevra M, Rammner B, Keihani S, Opazo F, Urban I, Ischebeck T, Sakib MS et al. (2018) Precisely measured protein lifetimes in the mouse brain reveal differences across tissues and subcellular fractions. Nat Commun 9, 4230.
46 Toyama BH, Savas JN, Park SK, Harris MS, Ingolia NT, Yates JR \& Hetzer MW (2013) Identification of long-lived proteins reveals exceptional stability of essential cellular structures. Cell 154, 971-982.

47 Studier FW (2005) Protein production by autoinduction in high-density shaking cultures. Protein Expr Purif 41, 207-234.

48 Burkhardt A, Pakendorf T, Reime B, Meyer J, Fischer P, Stübe N, Panneerselvam S, Lorbeer O, Stachnik K, Warmer M et al. (2016) Status of the crystallography beamlines at PETRA III. Eur Phys J Plus 131, 56.

49 Cianci M, Bourenkov G, Pompidor G, Karpics I, Kallio J, Bento I, Roessle M, Cipriani F, Fiedler S \& Schneider TR (2017) P13, the EMBL macromolecular crystallography beamline at the low-emittance PETRA III ring for high- and low-energy phasing with variable beam focusing. J Synchrotron Rad 24, 323-332.

50 Kabsch W (2010) XDS. Acta Crystallogr D 66, 125132.

51 McCoy AJ, Grosse-Kunstleve RW, Adams PD, Winn MD, Storoni LC \& Read RJ (2007) Phaser crystallographic software. J Appl Crystallogr 40, 658674.

52 Afonine PV, Grosse-Kunstleve RW, Echols N, Headd JJ, Moriarty NW, Mustyakimov M, Terwilliger TC, Urzhumtsev A, Zwart PH \& Adams PD (2012) Towards automated crystallographic structure refinement with phenix.refine. Acta Crystallogr D 68, 352-367.

53 Emsley P \& Cowtan K (2004) Coot : model-building tools for molecular graphics. Acta Crystallogr D 60 , 2126-2132.

54 Williams CJ, Headd JJ, Moriarty NW, Prisant MG, Videau LL, Deis LN, Verma V, Keedy DA, Hintze BJ, Chen VB et al. (2018) MolProbity: More and better reference data for improved all-atom structure validation. Protein Sci 27, 293-315.

55 Laulumaa S, Blakeley MP, Raasakka A, Moulin M, Härtlein M \& Kursula P (2015) Production, crystallization and neutron diffraction of fully deuterated human myelin peripheral membrane protein P2. Acta Crystallogr F Struct Biol Commun 71, 13911395.

56 Cowieson NP, Edwards-Gayle CJC, Inoue K, Khunti NS, Doutch J, Williams E, Daniels S, Preece G, Krumpa NA, Sutter JP et al. (2020) Beamline B21: high-throughput small-angle X-ray scattering at Diamond Light Source. J Synchrotron Rad 27, 14381446.

57 Franke D, Petoukhov MV, Konarev PV, Panjkovich A, Tuukkanen A, Mertens HDT, Kikhney AG, Hajizadeh NR, Franklin JM, Jeffries CM et al. (2017) ATSAS 2.8: a comprehensive data analysis suite for small-angle scattering from macromolecular solutions. J Appl Crystallogr 50, 1212-1225. 
58 Svergun DI (1999) Restoring low resolution structure of biological macromolecules from solution scattering using simulated annealing. Biophys $J$ 76, 2879-2886.

59 Kikhney AG, Borges CR, Molodenskiy DS, Jeffries CM \& Svergun DI (2020) SASBDB: towards an automatically curated and validated repository for biological scattering data. Protein Sci 29, 66-75.

60 Thompson JD, Gibson TJ \& Higgins DG (2002) Multiple sequence alignment using ClustalW and ClustalX. Curr Protoc Bioinformatics 2, 2.3.

61 Gouet P, Courcelle E, Stuart DI \& Métoz F (1999) ESPript: analysis of multiple sequence alignments in PostScript. Bioinformatics 15, 305-308.

62 Cilia E, Pancsa R, Tompa P, Lenaerts T \& Vranken WF (2013) From protein sequence to dynamics and disorder with DynaMine. Nat Commun 4, 2741.

63 Hallin EI, Bramham CR \& Kursula P (2021) Structural properties and peptide ligand binding of the capsid homology domains of human Arc. Biochem Biophys Rep 26, 100975.

64 Maier JA, Martinez C, Kasavajhala K, Wickstrom L, Hauser KE \& Simmerling C (2015) ff14SB: Improving the Accuracy of Protein Side Chain and Backbone Parameters from ff99SB. J Chem Theory Comput 11, 3696-3713.
65 Krieger E \& Vriend G (2015) New ways to boost molecular dynamics simulations. J Comput Chem 36, 996-1007.

66 Berg Klenow M, Camillus Jeppesen J \& Simonsen AC (2020) Membrane rolling induced by bacterial toxins. Soft Matter 16, 1614-1626.

\section{Supporting information}

Additional supporting information may be found online in the Supporting Information section at the end of the article.

Movie S1. Time-lapse films of P2 variants interacting with supported double membrane bilayers.

Movie S2. Time-lapse films of P2 variants interacting with supported double membrane bilayers.

Movie S3. Time-lapse films of P2 variants interacting with supported double membrane bilayers.

Movie S4. Time-lapse films of $\mathrm{P} 2$ variants interacting with supported double membrane bilayers.

Table S1. Forward primers for the P2 variants for mutagenesis. 